\title{
El progreso del conocimiento de la estructura geológica del noroeste peninsular hasta principios de los años 70
}

\author{
M. Julivert \\ Real Academia de Ciencias y Artes de Barcelona. \\ julizama@wanadoo.es
}

\begin{abstract}
RESUMEN
El objetivo de este artículo es el de analizar el progreso en el conocimiento de la tectónica del NW peninsular, desde los primeros mapas y los datos aislados del s. XIX hasta llegar al modelo actualmente aceptado, que queda ya establecido a principios de los años 70. La zona que se va a analizar tiene el particular interés de representar la sección completa de una cordillera, con tres areas claramente delimitadas, que de este a oeste son: una zona externa no metamórfica con mantos de despegue, una zona con pliegues tumbados y desarrollo de foliaciones, y una zona más interna, con alto grado de metamorfismo, abundancia de granitos y unos complejos cabalgantes con rocas básicas y ultrabásicas. No se analizan otras ramas de la geología como son la estratigrafía, paleontología, petrología, sedimentología etc. Se dan tan sólo algunas referencias a los primeros pasos dados en el establecimiento de la sucesión estratigráfica, ya que sin este conocimiento no puede avanzarse en la interpretación tectónica.
\end{abstract}

Palabras clave: Historia de la geología, NW de España, Estructura herciniana.

\section{The progress of knowledge of the geological structure of the northwest of the lberian peninsular until the early 1970 s}

\begin{abstract}
The aim of this article is to analize the evolution of the tectonic knowledge of the northwestern part of Spain, from the first geological maps and the first isolated tectonic data to the model established at the beginning of the seventies. The area to be analized has the interest of representing a complete cross-section of an orogenic belt, with three clearly delimited areas, from east to west: an external, non-metamorphic part, with décollement nappes, a fold-nappe area with increasing metamorphism from east to west, and an internal western part with high-grade metamorphim, granites, and basic/ultrabasic overriding complexes. In this article no other branches of the geology, such as stratigraphy, paleontology, petrology, sedimentology, etc, are considered. Only when dealing with the first geological papers published on the area, some references to the stratigraphy are made, as without the stratigraphical succession being established no tectonic interpretation is possible.
\end{abstract}

Keywords: History of Geology, NW Spain, Hercynian structure. 


\section{Introducción}

En este artículo se pretende analizar el modo como se ha ido estructurando el conocimiento de la geología del NW peninsular, desde el momento en que se realizaron las primeras observaciones geológicas y se levantaron los primeros mapas hasta el momento en que la cartografía del NW peninsular y el conocimiento de su estructura quedan basicamemente establecidos. El momento en que se alcanza este conocimiento marca un cambio en el rumbo de las investigaciones geológicas en todos los países. Este cambio significa el final de los estudios básicamente descriptivos destinados a conocer las características geológicas de una región y conduce a la exploración de nuevos temas y con nuevos planteamientos y nuevas problemáticas, que no serán tratados aquí. El NW de la Península
Ibérica es un buen sector de la Cordillera Herciniana para llevar a cabo el análisis propuesto, ya que es un segmento de dicha Cordillera en que se pasa desde la zona más externa no metamórfica, con una serie de mantos de despegue, situada al $\mathrm{E}$, a una zona con pliegues tumbados y con un metamorfismo creciente de $\mathrm{E}$ a W, hasta las zonas más internas con alto grado de metamorfismo y abundancia de granitos. El objeto de este artículo es pues describir como se ha ido conociendo la estructura de este sector de la Cordillera Herciniana. Por consiguiente, van a dejarse de lado los progresos en otros campos de la geología, aunque al principio tendrán que hacerse algunas referencias a la estratigrafía. Otras materias de desarrollo más reciente, posteriores a las fechas con las que termino este artículo, como la geocronología, la geoquímica o la geología isotópica no serán por tanto consideradas.
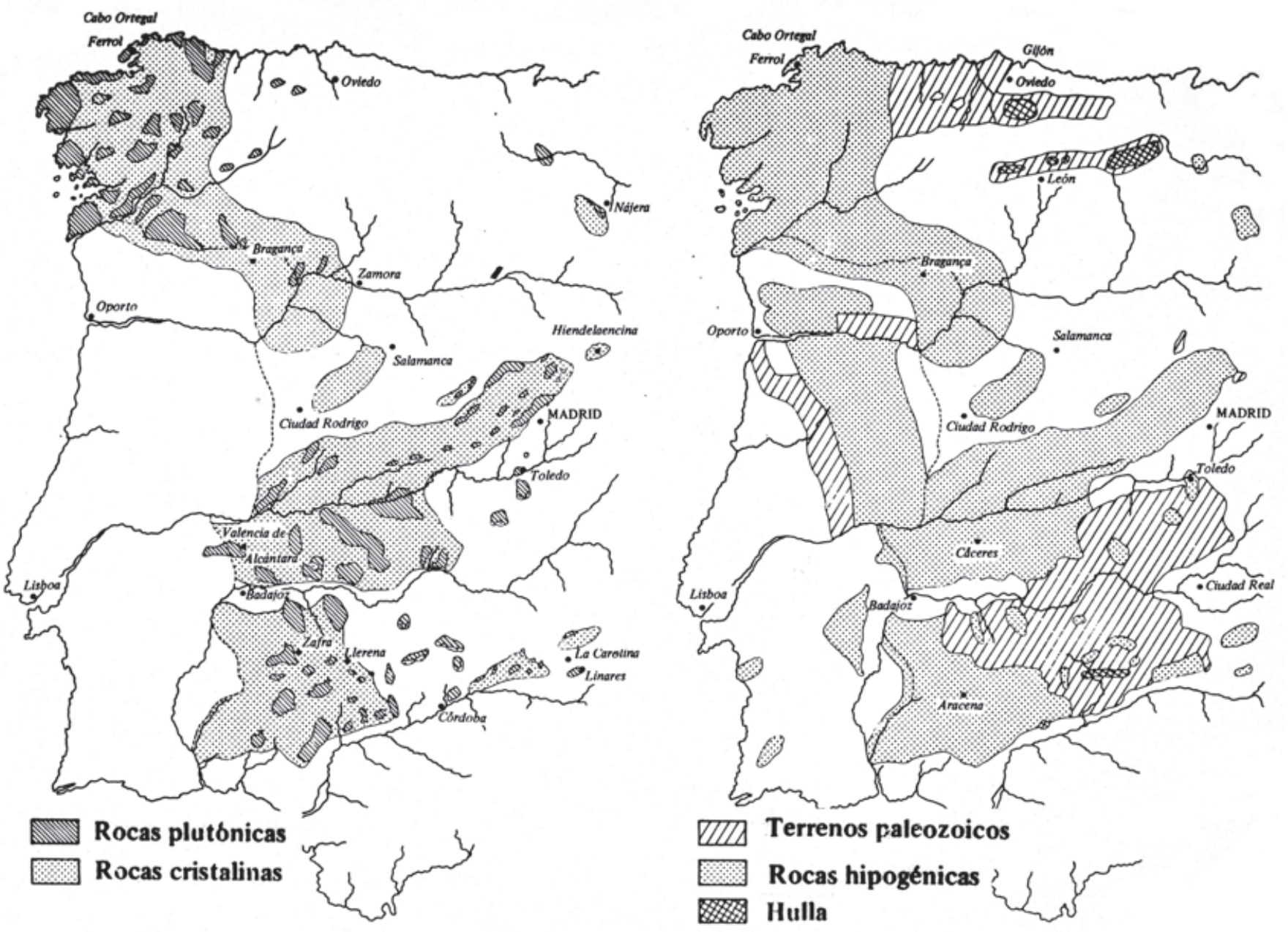

Figura 1. Mapa del Macizo Ibérico, según Ezquerra del Bayo (1850-57).

Figure1. Map of the Iberian Massif, according to Ezquerra del Bayo (1850-57). 


\section{La delimitación del Macizo Ibérico y la síntesis de Ezquerra del Bayo}

Hacia mediados del siglo XIX se publican ya los primeros bosquejos geológicos de Europa y en España aparecen los primeros mapas generales, como el de Verneuil y Collomb (1864), el de Maestre (1864) y el mapa posterior de Botella (1879). Con ello queda de manifiesto la existencia de una parte esencialmente mesozoico-terciaria, al este y sureste de la península, y un gran núcleo pre-mesozoico, al oeste. Esta distribución se muestra igualmente en los trabajos sintéticos de Ezquerra del Bayo (1850, 1850-1857) (fig. 1), Macpherson (1879) y Calderón (1885). A la parte occidental antigua de la península se la denominó Meseta Central o Meseta lbérica (Calderón, 1885), término que ha pasado a Macizo lbérico, ya que la denominación de "Meseta" tiene una connotación geomorfológica, y por tanto debe ser reservada para descripciones de este tipo.

\section{El problema del "granito primordial"}

La primitiva corteza, que se suponía de naturaleza granítica (el Ilamdo "granito primordial"), se pensaba que podía existir en algún lugar, por lo que se hace referencia a este problema en varias publicaciones. Al tratar este tema será necesario considerar trabajos que se refieren a diversas zonas de la península, ya que el problema del "granito primordial" fue un problema muy candente que se trata en publicaciones que se refieren a áreas muy diversas, y las ideas que sobre ello se expresan afectan a todas las áreas graníticas de la península, aunque no existen trabajos concretos referidos a este tema sobre su parte noroccidental.

Aunque con anterioridad existian los trabajos de Schulz (1835, 1858a, 1858b) sobre Galicia y Asturias, el conocimiento sistemático del Macizo Ibérico, y de la península en general, se inicia en la segunda mitad del s. XIX con la elaboración del mapa geológico nacional a escala 1:400.000 y con los trabajos petrográficos de Macpherson (1883-84, 1886) sobre los terrenos "arcaicos", y concretamente sobre Galicia.

En la época en que se realiza el mapa geológico, la escala estratigráfica básica, para los terrenos fanerozoicos, y el origen ígneo del granito estaban ya establecidos. En España no se habían producido publicaciones basadas en los conceptos neptunistas, más que en casos aislados, y siempre por parte de autores extranjeros, especialmente referentes al Pirineo (Santanach, 2015), favorecido ello por su carácter de cordillera lindante con Francia. Por tanto, por lo que se refiere a la investigación del noroeste peninsular, esta se inicia cuando las interpretaciones neptunistas habían sido ya abandonadas.
Las relaciones intrusivas del granito con su encajante y el metamorfismo que producen, son descritas repetidamente en las memorias provinciales y en la explicación general de Mallada, pero la idea que se tenía de que la primitiva corteza de laTierra era de naturaleza granítica, y que estaba preservada en algunos puntos, planteaba una serie de problemas, a pesar de que esta primitiva corteza granítica no se encontraba en ninguna parte. Asimismo, existía una confusión sobre el llamado "estrato cristalino" o "Sistema Estrato Cristalino". Mallada (1895, p. 27) en el tomo 1 de la explicación del mapa dice: "en esta explicación del Mapa Geológico de España que tiene objeto muy distinto al de un tratado elemental de geología nada diríamos del origen del granito, de cuyo asunto se ha prescindido en la mayor parte de las memorias descriptivas (se refiere a las memorias provinciales), si no fuere porque en algunas de ellas se ha discutido algo este problema".

Como muestra de esta contradicción entre la idea de que existía un granito "primordial" o "primigenio" y los hechos de observación, puede citarse el siguiente párrafo de Egozcue y Mallada (1876, p. 72): “En la provincia que estudiamos (Cáceres) no sólo hay granitos eruptivos, que bajo tal punto de vista no pueden recibir la denominación de primordiales, sino que acaso a aquella categoría correspondan en su totalidad" y en términos parecidos se expresa Maestre (1880, p. 88).

Sobre el origen del granito, Casiano de Prado (1864), aunque reconoce "su ascensión del interior de la Tierra", también dice que "la explicación de cómo se formó esta roca deja todavía bastante que desear". En cuanto a las ideas concernientes a una primitiva corteza, es ilustrativo el siguiente texto de Cortázar (1890, pp. 119-122) que habla de un origen múltiple del granito: "Una vez suficientemente enfriado nuestro Globo debió producirse en la superficie viscosa una capa de rocas anhidras, en cuya composición estarían los elementos que ahora se hallan en los mares y las capas terrestres". Pero Cortázar reconoce que la textura de esta roca no podría haber sido la del granito, si no alguna clase de lava, de modo que después de unas explicaciones extraordinariamente confusas, acaba diciendo: "En resumen, el granito es una roca en la cual el metamorfismo regional es evidente, debe su textura a las acciones moleculares que obraron lentamente, pero persistiendo millones de siglos". Estas dudas quedan bien manifiestas con la siguiente frase de Delesse (1875), que en una discusión sobre el origen del granito se refiere a las ideas de Knop diciendo: "para Knop el granito es una roca eruptiva, en la que el metamorfismo ha tenido lugar mediante lo que llama metasomatismo. Proviene de una roca traquítica, solidificada, sometida a la acción del agua, de la 
presión y de una temperatura más o menos elevada, correspondiente a las grandes profundidades del interior de la Tierra".

Si bien la idea de una corteza primitiva granítica quedó ya desechada, los debates sobre el granito persistieron durante largo tiempo, pero en estos debates no hay referencias a los granitos de Galicia, por lo que en lo sucesivo no se hará ninguna mención de ellos.

\section{La primera cartografía y las primeras dataciones. La columna estratigráfica en los trabajos publicados ha- cia mitad del siglo XIX}

Antes del Mapa Geológico de España 1:400.000, preparado en la segunda mitad del s. XIX y cuyo original fué presentado en 1883 y publicado unos años más tarde (para más datos y bibliografía sobre el tema, ver Rábano y Aragón, 2007, Julivert, 2014; Rábano, 2015,2019 ) no se había producido ningún estudio sistemático del Macizo Ibérico. Los primeros datos no puntuales sobre el mismo son los mapas regionales de Schulz sobre Galicia, y más tarde sobre Asturias (Schulz, 1835, 1858a,b), y la memoria de Prado sobre la provincia de Madrid (Prado, 1864). Estos mapas, aunque constituyen una parte muy minoritaria si se considera la extensión de todo el macizo, representan un trabajo de detalle, muy meritorio para la época. Los mapas de Schulz, especialmente el de Asturias, son particularmente interesantes. Aparte de dibujarse ya el arco asturiano, a pesar de no poder estar completo, ya que no se incluye la vertiente leonesa de la cordillera, hay una serie de datos que muestran que Schulz era un buen observador, tema sobre el que se tratará más adelante.

Centrando la atención en el NW peninsular, la única visión global de Asturias y de Galicia la dan los trabajos de Schulz $(1835,1858 a, b)$, quién publicó una "Descripción geognóstica del reino de Galicia, acompañada de un mapa petrográfico de este país", una "Descripción geológica de la Provincia de Oviedo" y un "Atlas Geológico y Topográfico" de la misma, aunque siguiendo las pautas de aquellos tiempos, su estudio se adapta a los límites provinciales, y no abarca por tanto todo el conjunto del Paleozoico cantábrico, que comprende también una parte de León. En resumen, Schulz reconoce y sitúa geográficamente los afloramientos del Silúrico, Devónico y Carbonífero en Asturias y reconoce el tipo de rocas presente en cada caso, pero no puede aun ordenar las diferentes rocas en una sucesión estratigráfica.

En su publicación sobre Asturias, Schulz $(1858 a, b)$ establece una primitiva distribución de los terrenos. Según él, la parte oeste de Asturias está formada por terrenos silúricos (no se olvide que el Ordovícico estaba englobado en el Silúrico) que consistían en pizarras, cuarcitas y "grauwakes"; cita también la presencia de algún granito (Boal) y de terrenos "pseudocarboníferos", que en algunas partes aparecen "enclavados" en el terreno antiguo o Silúrico (de ello se tratará más adelante). Del Devónico, que reconoce que se encuentra en la parte central de Asturias, dice que "ocupa una zona algo curva [...] que se extiende de sur a norte a través de la provincia [...] ligada por el sur a igual terreno en las montañas de León". Según Schulz, el Devónico está formado "por cuatro series o clases (de rocas), a saber: rocas areniscas o areniscosas, rocas pizarrosas, rocas margosas y rocas calizas", pero sin establecer ningún tipo de sucesión. Schulz reconoce la existencia también de terrenos carboníferos en esta área (Teverga, Puerto Ventana). Por lo que respecta al Carbonífero, dice que su parte inferior está formada por caliza, a la que llama "caliza carbonera", "encimera" o "de montaña", nombre esta último que ha persistido hasta la actualidad. Esta caliza se interpone "entre el terreno devoniano que queda debajo [...] y el Carbonífero verdadero que se apoya encima". Schulz reconoce que esta caliza se encuentra tanto al E como al W de la "región carbonífera rica del centro", pero reconoce su mayor importancia al $E$, donde coexiste con crestones de cuarcitas, y fajas de pizarras y areniscas, que dice que deben ser de la misma edad, aunque no se atreve a afirmarlo taxativamente y aunque da a estos materiales el nombre de "subcarboníferos". A continuación, describe la "Región carbonífera rica del centro", es decir la Cuenca Carbonífera Central Asturiana donde cita la existencia de capas de conglomerados y raras capas de caliza, citando una lista de fósiles, recogidos mayoritariamente por Paillette y clasificados por Verneuil.

En resumen, los trabajos que permitieron una primera visión de la geología del conjunto de Asturias y Galicia fueron los de Schulz. En Asturias, este autor reconoce y sitúa geográficamente los afloramientos del Silúrico, Devónico y Carbonífero y reconoce el tipo de rocas presente en cada caso, pero no puede aun ordenar las diferentes rocas en una sucesión estratigráfica.

Hacia mediados de siglo, la sucesión cronoestratigráfica estaba ya perfilada, y en España se habían encontrado también las primeras faunas del Cámbrico (Barrande, 1860; Prado, 1860; Verneuil y Collomb, in Prado, 1860; Macpherson, 1878), que es el último periodo en ser establecido en la escala estratigráfica. A los trabajos citados hay que añadir los cortes, algo más tardíos, de Mallada y Buitrago (1878) del Cámbrico cantábrico, que son los dos primeros cortes coherentes del Cámbrico de Asturias (Zamarreño, 1972).

No obstante, al describir la geología de España, Ez- 

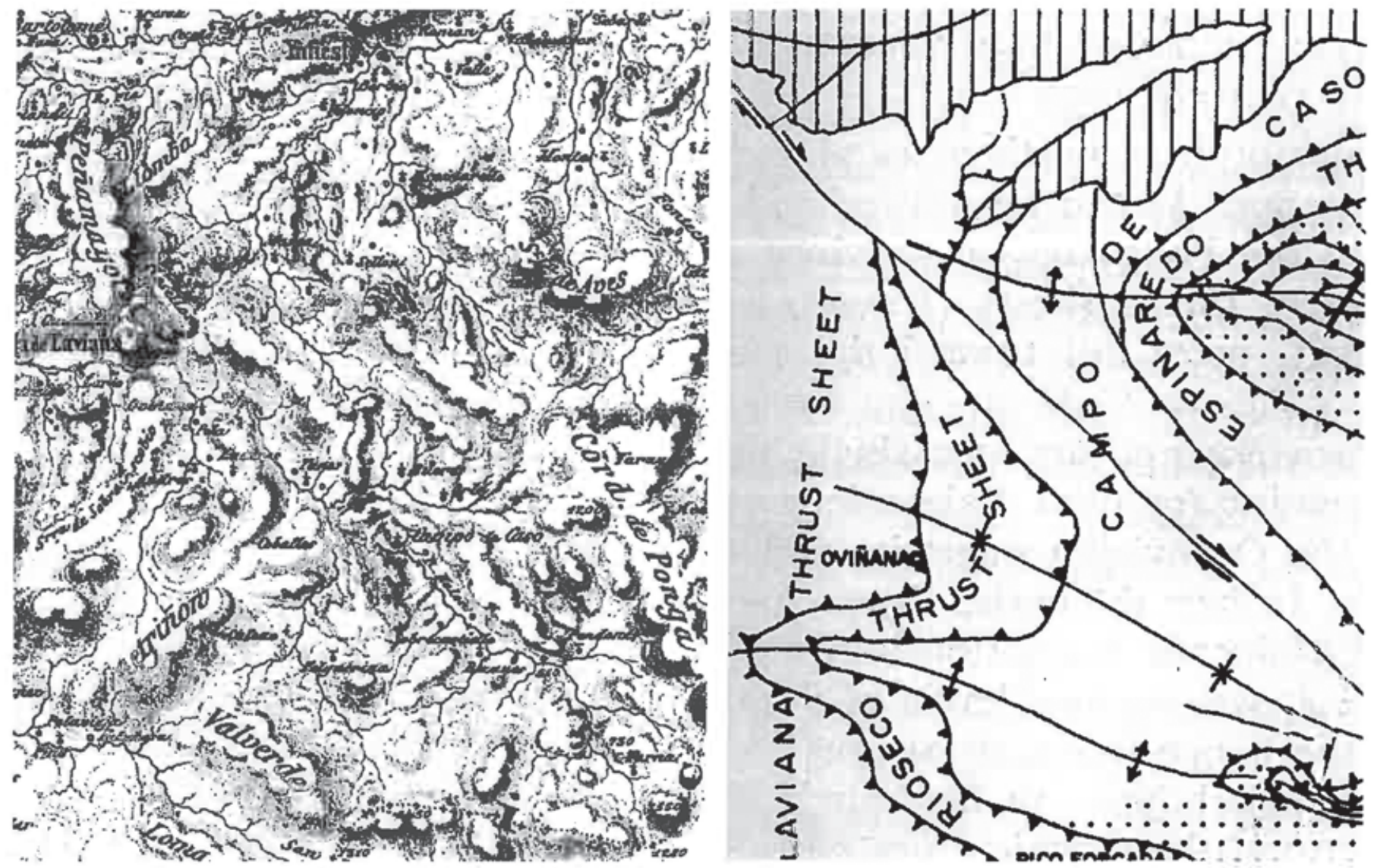

Figura 2. Una parte del mapa topográfico de Schulz sobre Asturias (1858b) y esquema estructural moderno (Julivert, 1971). Comparando ambas figuras, puede verse como Schulz dibuja la topografía con las crestas curvas, como hace el trazado de las escamas, a pesar de lo cual ello no se traduce en el mapa geológico.

Figure 2. A part of the topgraphical map by Schulz about Asturias (1858b) and a modern structural scheme (Julivert, 1971). When both figures are compared we can see that Shulz drew the topography with curved ridges as well as the tracing of the tectonic slices; both features are not, however, shown in the geological map.

querra del Bayo (1850-1857), duda aún de muchas atribuciones estratigráficas. Así por ejemplo, en la p. 125 dice que: "durante la época liásica habría habido un intervalo de tiempo en el cual las condiciones climáticas de aquella localidad [...] fueron propicias o adecuadas al desarrollo y crecimiento de plantas análogas a las del llamado periodo Carbonífero", y más adelante añade que: "no hay hasta ahora reunidos [...] los datos suficientes para poder considerar con exactitud el lugar que el llamado terreno Carbonífero debe ocupar en la serie general de los terrenos geológicos".

\section{La visión general que puede obtenerse del NW pe- ninsular a partir de los mapas de Schulz}

Los mapas de Schulz ponen de manifiesto un par de rasgos esenciales de la geología del noroeste peninsular, aunque naturalmente no pudieron ser to- mados en consideración por su autor. Por una parte, en el mapa de Asturias se observa el trazado del arco asturiano. Por otra parte, colocando juntos los dos mapas de Asturias y Galicia, se ve el paso de este a oeste, desde los terrenos del Paleozoico más superior (Devónico, Carbonífero), no metamórfico, de Asturias oriental, a los terrenos pizarrosos de Paleozoico inferior de Asturias occidental, hasta los terrenos graníticos y metamórficos de Galicia. Este hecho representa el paso de las zonas externas, frontales, de una cordillera a las zonas más internas, pero en la época de Schulz estos conceptos no estaban aun establecidos.

\section{Observaciones sobre hechos concretos}

En algunos trabajos del s. XIX se encuentran hechos de observación muy correctos, a pesar de que estos no puedan interpretarse y a veces ni siquiera se 


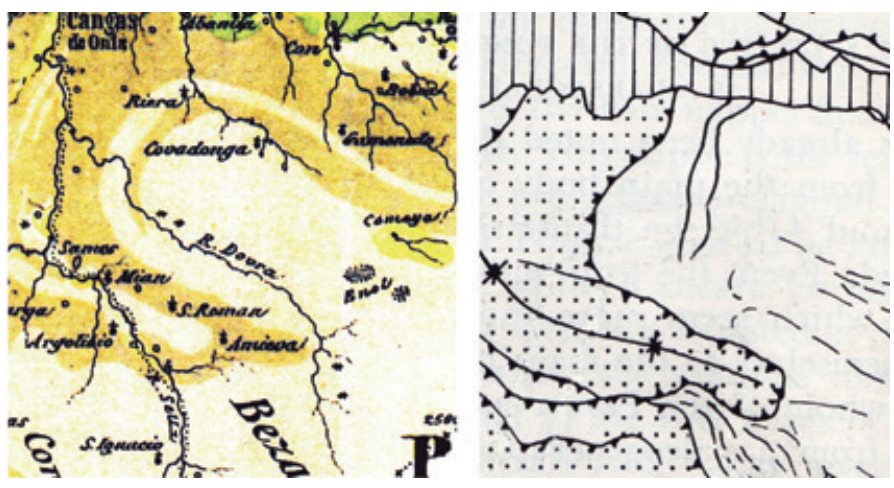

Figura 3. Izquierda: Fragmento del mapa geológico de Asturias de Schulz (1958a), al S de Cangas de Onís. Derecha: Esquema tectónico de una parte del Manto del Ponga, según Julivert (1971), en el que puede verse cómo el Manto del Ponga en el sector de Amieva sigue el mismo trazado que en el mapa de Schulz, aunque, como es natural, éste no pudo interpretar la estructura.

Figure 3. On the left: a fragment of the geological map of Asturias by Schulz (1958a), to the south of the Cangas de Onís. On the right: tectonic diagram of the Ponga nappe in the Amieva sector (Julivert, 1971) showing that the Ponga nappe trace, in this locality is the same that in Schulz's map although, of course, he could not interpret the structure.

tiene noción de que tengan un significado.

Algunas de estas observaciones se refieren a estructuras tectónicas que no se sabían interpretar en aquella época. Un ejemplo son las observaciones de Paillette y de Schulz que, siendo correctas, dichos autores no pudieron interpretar. Paillete (1845) dice con respecto a la posición del Carbonífero de Arnao: "falta ahora decidir si las hullas secas flamígeras y poco carbonosas de la cuenca de Arnao pertenecen al terreno siluriano sobre el que reposan, o bien si corresponden verdaderamente a la formación devoniana que las cubre inmediatamente". El terreno carbonífero de Arnao es Estefaniense, se apoya discordantemente sobre su sustrato y es cabalgado por el Devónico. En Paillete hay pues unos hechos bien observados, pero le falta una interpretación, al no haber datado el Carbonífero y al no considerar la posibilidad de un cabalgamiento, estructura desconocida en la época. Schulz plantea dudas parecidas respecto al Carbonífero de Tineo, diciendo: "si el terreno carbonífero debe, a pesar de su situación concordante con el Siluriano, considerarse como de formación posterior, será esto una prueba más de la enorme dislocación del terreno siluriano, que en Tineo se encuentra como recostado sobre el Carbonífero". Una vez más, la observación es correcta o casi correcta, aunque el Carbonífero deTineo (Estefaniense) no es concordante sobre el Silúrico (en realidad el Precámbrico), de modo que el problema estriba en la dificultad en realizar una buena datación y en interpretar la tectónica.

Algunos datos de significación estructural se encuentran en los mapas de Schulz. Así, por ejemplo, en el mapa topográfico de Asturias (Schulz, 1958b), se puede leer en el relieve el trazado, por lo menos en parte, de las escamas de Rioseco, Laviana y Campo de Caso (fig. 2), a pesar de que en la época se confundían alineaciones montañosas y divisorias hidrográficas, y aunque luego en el mapa geológico ni siquiera el trazado de los estratos permita adivinarlas. Un segundo caso, también de Schulz, es el sinclinal de Sebarga, en el Manto del Ponga (Schulz 1858a). El sinclinal está perfectamente dibujado, con una exactitud que no tienen otras partes del mapa, a pesar de ser una estructura relativamente pequeña y cuyo carácter cabalgante no podía interpretar (fig. 3).

Otro caso, este ya más interpretativo es el esquema que dan Mallada y Buitrago (1878) de los frentes de cabalgamiento al sur de Pajares, en la vertiente leonesa. En este sector, el Cámbrico cabalga sobre capas más modernas, lo que reconocen Mallada y Buitrago en su corte, dibujando las superficies de contacto cabalgantes y paralelas a la estratificación, como realmente están. Los citados autores piensan, no obstante, que la estructura debe haberse formado en dos etapas y suponen que durante la primera se formaron fallas verticales que después habrían rotado (fig. 4). Esta interpretación es imposible ya que significaría pasar mediante una rotación, de fallas verticales cortando los estratos a superficies de fractura paralelas a la estratificación.

\section{La caracterización de la columna estratigráfica en la segunda mitad del siglo XIX y primeras décadas del siglo $X X$}

En la segunda mitad del S. XIX se empiezan ya a establecer sucesiones estratigráficas más detalladas. La labor más importante en el campo de la estratigrafía en el NW de la península fue la realizada por Charles Barrois (1882), que estudió los terrenos paleozoicos de Asturias y Galicia. La estratigrafía establecida por Barrois, que creó una serie de formaciones en el sentido moderno de la palabra, es todavía la utilizada actualmente, especialmente por lo que se refiere a los terrenos precarboníferos, con las modificaciones a que lógicamente ha conducido el paso del tiempo (para lo referente al Carbonífero en Barrois, verTruyols, 1982). Otros trabajos de esta época, aunque menos significativos o más puntuales, son los de Paillete (1845), Paillete y Verneuil (1846), Zeiller (1884) y Grand'Eury (1887).

Por lo que respecta a la vertiente $\mathrm{S}$ de la Cordillera Cantábrica, en su sector leonés, el estudio sistemático de la estratigrafía fue realizado por Compte en los años treinta. Entre 1934 y 1938 Compte publicó varias notas previas a su tesis, principalmente en los Comp- 
tes Rendus de la Academia de Ciencias de París, pero la guerra civil española y después la Guerra Mundial interrumpieron su trabajo. Compte presentó su tesis en Lille en 1946 (Zamarreño, 1972), pero su obra quedó inédita. Finalmente, en 1959 fue publicada como una Memoria del IGME. De todos modos, la estratigrafía presentada por Compte a través de sus notas cortas fue ampliamente conocida y aceptada en los estudios posteriores, antes de la publicación de su obra completa.

Estos trabajos se citan aquí, a pesar de su índole estratigráfica, porque con ellos se establece la sucesión estratigráfica en las dos vertientes de la Cordillera y porque han servido de base para cualquier estudio posterior ya que, sin el conocimiento previo estratigráfico, por lo menos a grandes rasgos, no es posible ninguna interpretación tectónica. Con posterioridad se ha progresado mucho, se han dado muchas precisiones sobre la sucesión estratigráfica, se han realizado multitud de estudios paleontológicos, sedimentológicos o de análisis de cuencas y se han determinado las edades con mucha mayor precisión, pero todo ello pertenece ya a otros campos de la Geología, por lo que a partir de este momento estos trabajos no serán ya tenidos en cuenta en el análisis que sigue.

\section{La región cantábrica vista por los tectónicos franceses como una cordillera de mantos alpídicos}

El descubrimiento de los mantos alpinos trajo como consecuencia la búsqueda de este tipo de estructuras en otras cordilleras. El conocimiento insuficiente de muchas de ellas fue la causa de que se hicieran interpretaciones precipitadas y erróneas.

Con referencia a la Cordillera Cantábrica, el primer trabajo en este sentido fue el de Termier (1905), que en una breve nota afirma que toda la provincia de Santander es un país de mantos, posteriores al Nummulítico, estructura que se prolongaría por Asturias. Esta idea dio pie a que Mengaud iniciase una Tesis en esta región, con la consiguiente aparición de una serie de notas por parte del mismo Mengaud (1908, 1910, $1914,1920)$ y de Bertrand y Mengaud (1912a, 1912b, 1912c) insistiendo en esta interpretación. Termier, por su parte, publicó también varias notas cortas al respecto (Termier, 1918a, 1918b, 1918c, 1918d). Con estas interpretaciones, la Cordillera Cantábrica aparece como una continuación de los Pirineos, por lo que se acuña el nombre de "Pirineos Cantábricos" (Bertrand y Mengaud, 1912c). Mengaud considera la existencia de 3 conjuntos ("series"), alóctonos los dos superiores, dudoso el más bajo. Bertrand y Mengaud se inclinan por el origen meridional de los mantos y los

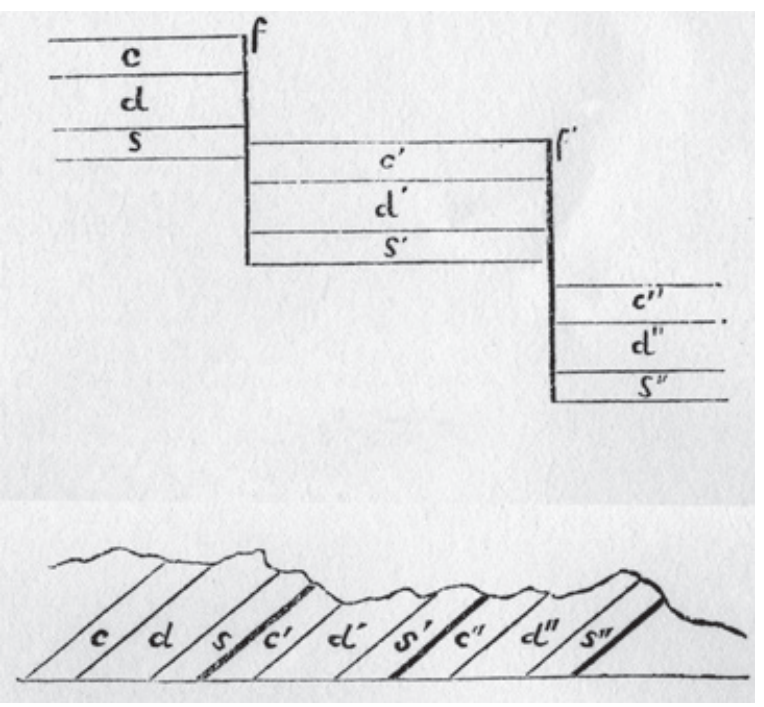

Figura 4. Interpretación de Mallada y Buitrago (1878) de las escamas de la vertiente leonesa de la Cordillera Cantábrica. Estos autores suponen que la estructura se ha formado en dos etapas, la primera dando una serie de fallas verticales (parte superior) y la segunda mediante una rotación conduciendo a la situación actual (parte inferior).

Figure 4. Interpretation by Mallada and Buitrago (1878) of the tectonic slices of the Leonese slope of the Cordillera Cantábrica. These authors hypothesized that the the structure was formed in two stages, the first producing a series of vertical faults (the upper section) and the second via a rotation leading to the the prenent day disposition (the lower section).

consideran equivalentes a los mantos norpirenaicos. Termier considera que las estructuras con dirección $\mathrm{N}-\mathrm{S}$ o NE-SW son de edad estefaniense, mientras que las E-W serían alpídicas, desconociendo la continuidad entre ambos grupos de estructuras, debidas al arco cantábrico, visible ya en Schulz y señalado por Suess. En cuanto a la tectónica de mantos alpídicos, Termier se da cuenta de que todos los terrenos están ligados entre sí lo cual daría a los mantos unas dimensiones enormes, y plantea una serie de problemas que parece que le hacen dudar de la existencia de corrimientos alpinos, pero a pesar de estas dudas acepta la existencia de corrimientos postnumulíticos. Termier considera que los mantos proceden del norte y serían un avance del país cantábrico sobre la región tabular de Castilla.

Las ideas aloctonistas fueron cuestionadas por autores españoles como E. Hernández-Pacheco (1912, 1913), quien rechaza la denominación de "Pirineos Cantábricos", pero los trabajos de este autor eran de índole muy general y no aportaban nuevos datos al debate tectónico. También Patac se mostró contrario a la idea, pero sus trabajos estaban muy orientados hacia el carbón (Patac, 1920, 1932, 1933) y se ocupaban poco de problemas más amplios. Es con la aparición del volumen de Adaro (Adaro y Junquera, 1916) que se da un paso firme en el conocimiento del paleozoico 


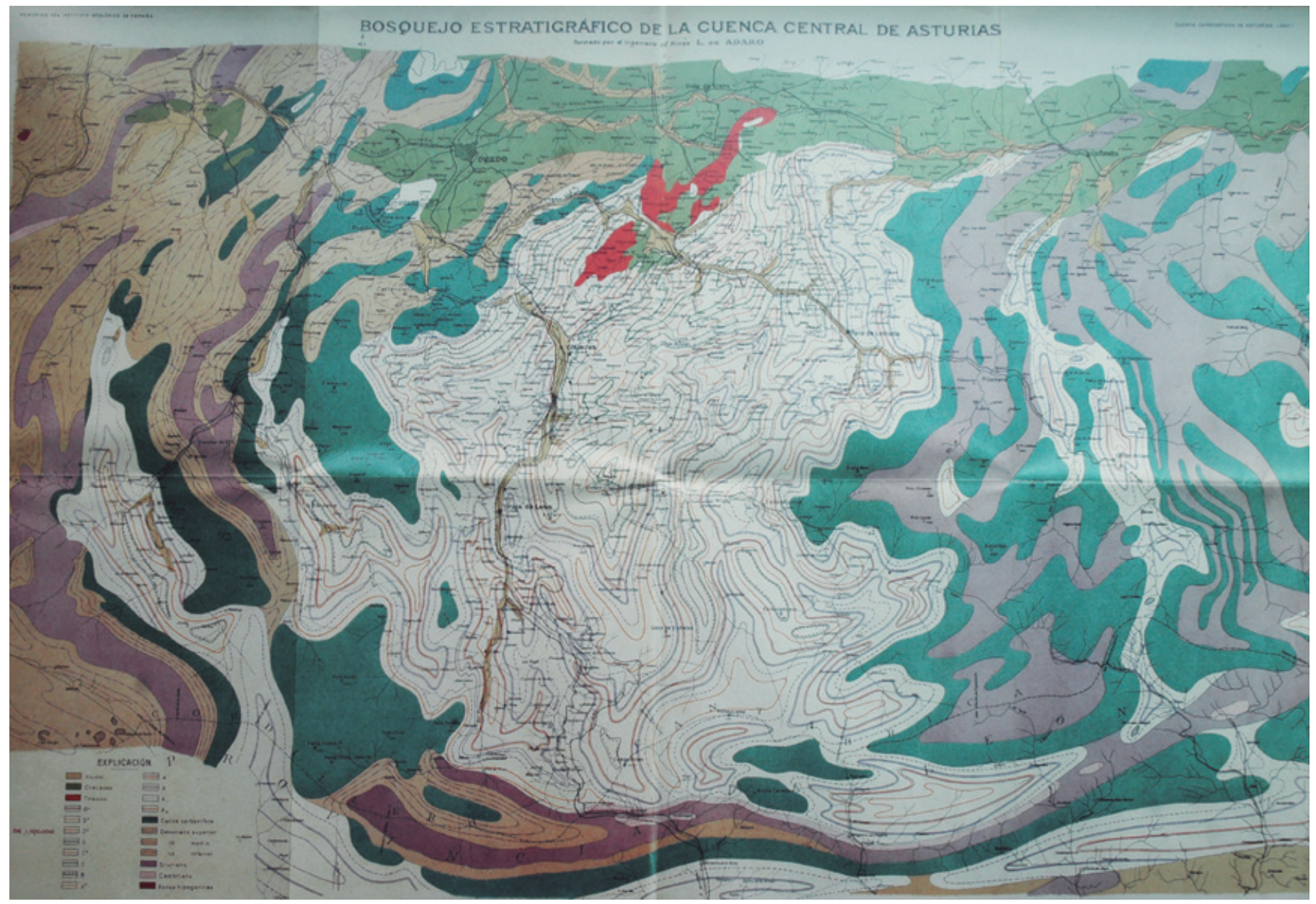

Figura 5. Mapa de la cuenca hullera central asturiana, según Adaro (1926).

Figure 5. Map of the central Asturian coal basin, according to Adaro (1926).

de Asturias-León. Dichos autores dedican las páginas 88 a 103 a discutir la cuestión, mostrándose contrarios a la interpretación aloctonista alpina, y aunque este capítulo es más bien confuso, con sus mapas queda patente que dicha interpretación no puede mantenerse. Finalmente, en 1932, Mengaud publicó una nota corta en la que hace una serie de rectificaciones, que si bien de un modo no muy taxativo, son la rectificación a sus interpretaciones.

Para terminar, en 1934 Karrenberg estudió el Mesozoico de la zona litoral de Asturias oriental, poniendo en evidencia su carácter de cobertera poco deformada, recubriendo al paleozoico plegado, y afectada simplemente por fallas, con lo que las ideas de la existencia de mantos de tipo alpino, nunca realmente del todo aceptadas, se dejaron ya totalmente de lado.

Este tipo de interpretaciones precipitadas, sin reunir datos suficientes, y sin saber ni tan sólo con qué tipo de cordillera se estaba tratando, fueron la causa del descrédito que sufrieron los mantos de corrimien- to, no sólo en España sino también en otros países (de centroeuropa y la Unión Soviética, especialmente). Con la llegada de la escuela de Stille, y las interpretaciones de Ashauer en el Pirineo, las ideas autoctonistas se afianzaron en España, con la excepción de las Béticas.

\section{Los trabajos en las primeras décadas del siglo XX. La obra de Adaro}

A principios del s. XX surge la figura de Adaro, que lleva a cabo una labor importante en Asturias, dedicada principalmente al estudio del hierro y el carbón. Respecto a los yacimientos de hierro (Adaro y Junquera, 1916), Adaro estudia las capas ferruginosas silúrico-devónicas y da un mapa muy expresivo de la parte central de Asturias. Adaro no está particularmente motivado por problemas estratigráficos, de modo que en la estratigrafía del Devónico sigue simplemente a Barrois. No obstante, en su mapa sobre la Zona Fe- 


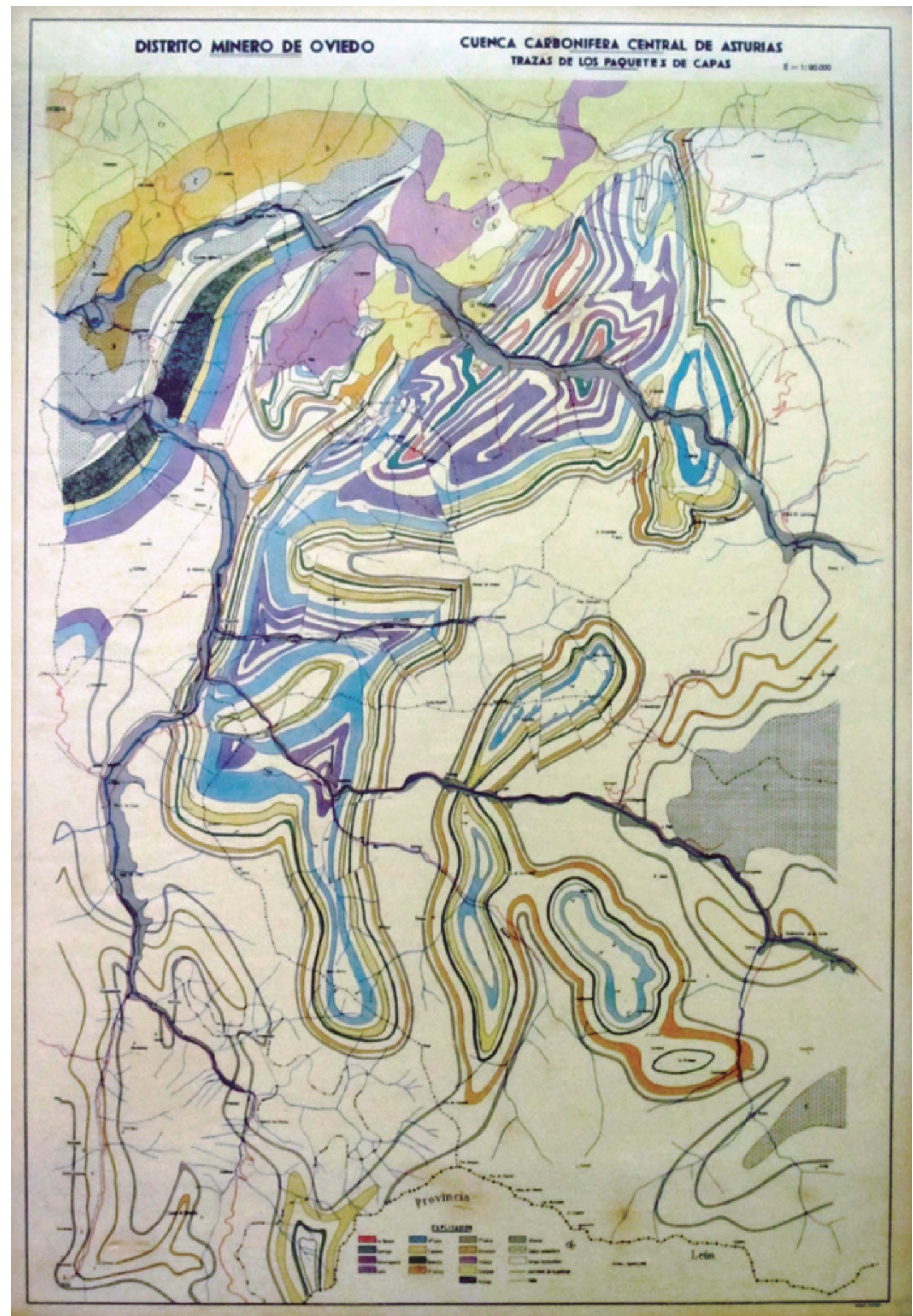

Figura 6. Mapa anónimo, sin fecha (aparecido probablemente en los años 40), conocido normalmente como "Mapa de los capataces", con el trazado de las capas basado en los datos procedentes de las explotaciones.

Figure 6. Undated anonymous map, which probably appeared in the 1940s, commonly known as the "Mapa de los capataces", tracing the strata from data from the exploitation of the mines. 


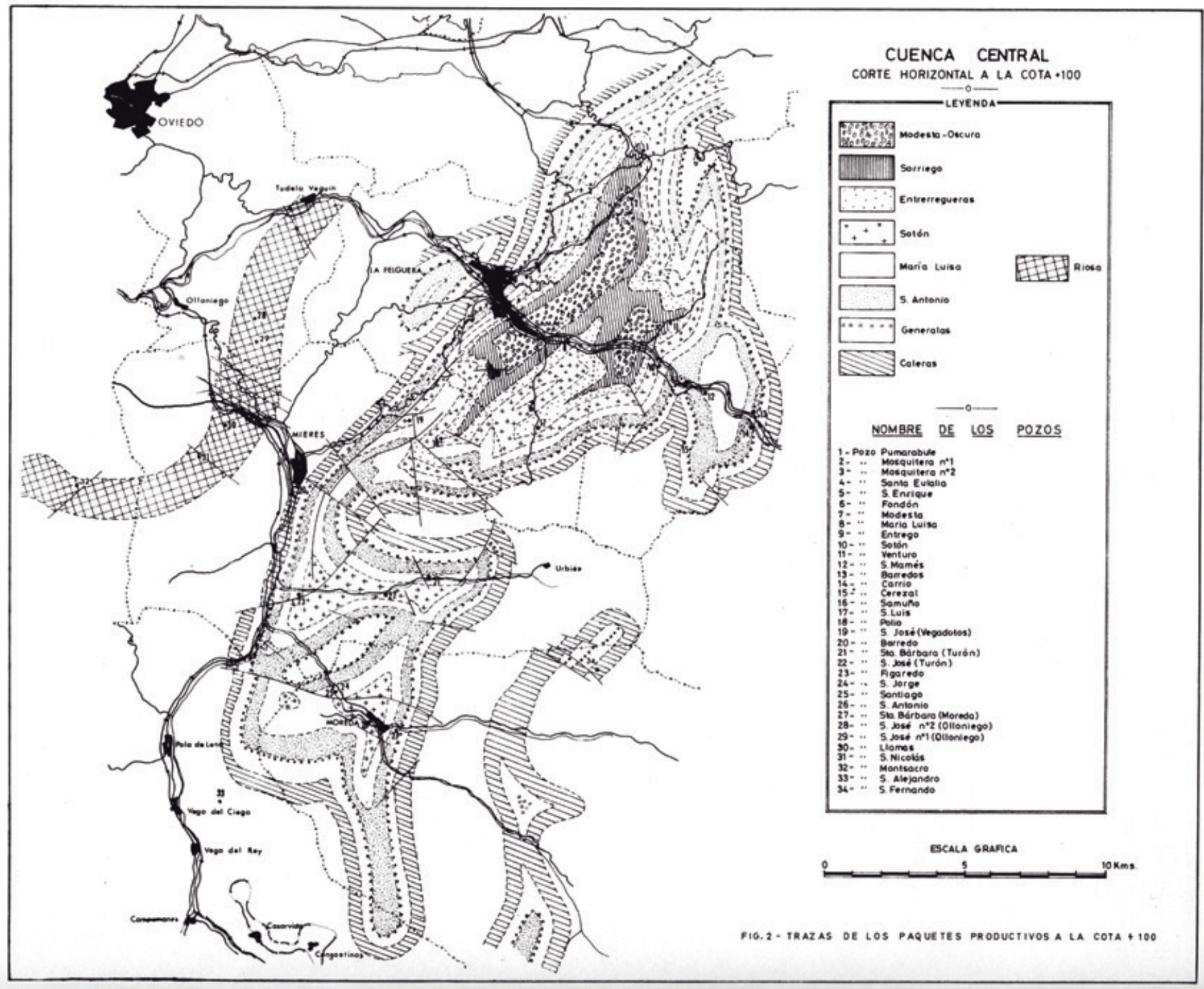

Figura 7. Mapa de la Cuenca Carbonífera, según García Loygorri (1971).

Figure 7. Map of the carboniferous basin, according to García Loygorri (1971).

rrífera Central de Asturias no diferencia más que dos niveles de areniscas en el Devónico, y ello le lleva a veces a dibujar más pliegues de los existentes. Adaro y Junquera destacan ya el hecho de la ausencia del Devónico en el oriente de Asturias, y el carácter transgresivo del Carbonífero sobre el Ordovícico, lo que implica una primera delimitación de la cuenca devónica.

Esta obra de Adaro, que no hay que olvidar que está dedicada especialmente al estudio de los yacimientos minerales, concretamente del hierro, fue publicada después de su muerte, preparada para la impresión por Junquera, que firma el volumen junto con Adaro, y con una parte sobre los "Criaderos de mineral de hierro de Los Oscos" y otra sobre los "Criaderos de hierro de la zona de Luarca" escritas por P. Hernández Sampelayo.

Respecto al carbón, Adaro, en una de sus publicaciones, se refiere a la posible prolongación de los niveles productivos de esta edad por debajo del Mesozoico de la zona litoral (Adaro, 1914), tema sobre el que insistirán Almela y Ríos años más tarde (1962). El tema de la prolongación de las capas de carbón bajo el mesozoico será un recurrente en la geología asturiana. Además, Adaro preparó un álbum de la Cuenca Carbonífera Central de Asturias (Adaro, 1926), publicado después de su muerte, en el cual, gracias a las labores mineras que se efectuaban en la Cuenca Carbonífera asturiana, pudo establecerse una sucesión estratigráfica de los paque- 
tes de las capas de carbón. Este mapa (fig. 5), referido a una zona con una potente sucesión estratigráfica, con pocos niveles guía que pudieran fácilmente trazarse en el campo, sólo podía ser realizado por un minero, ya que para su realización se requería un conocimiento de los paquetes de capas con carbón, su correlación entre las diferentes minas, y por tanto de su trazado por toda la extensión de la cuenca. Bastante más tarde, apareció un mapa publicado sin fecha y sin autores, en el que se indica solamente "Distrito Minero de Oviedo" (anónimo, sin fecha) y que se conoce informalmente como "Mapa de los Capataces" (fig. 6), en el que aparece el trazado en la cuenca de los diferentes paquetes productivos. Este mapa apareció probablemente en la década de los 40 . Ambos mapas permiten reconocer la estructura de la cuenca. Posteriormente se publicó el mapa de García Loygorri et al. (1971), basado igualmente en el laboreo de las minas (fig. 7).

\section{La existencia de un núcleo rígido Arcaico en la penín- sula vs. la edad hercínica de todo el Macizo}

A lo largo del s. XIX, la aportación de los geólogos españoles fue esencialmente el levantamiento del mapa geológico, consiguiéndose una cartografía que, junto con la de los geólogos portugueses, abarcaba toda la Península. En estos años se identifican también una serie de rocas ígneas y metamórficas, especialmente por parte de Macpherson (1879, 1883-84, 1886). Aunque sobre la estructura general del Macizo Ibérico nada podía decirse todavía, la publicación del mapa a escala 1:400.000, terminado en 1883, permitía ver ya que las rocas graníticas se disponían básicamente en la parte central de la Península y en Galicia. Calderón (1885) señala también que el núcleo del Macizo lbérico, al que denominó "tabla antigua" está formado por granito y gneiss " $y$ a ambos lados como adaptándose a las rocas anteriores y formando un todo inseparable con ellas, bajo el punto de vista orogénico, asoman los materiales paleozoicos". Esta frase indica un principio del conocimiento de cómo se disponen los distintos tipos de materiales en el Macizo Ibérico, la existencia de unas fajas orogénicas $y$, por tanto, aunque vagamente, un principio del reconocimiento de la estructura.

Calderón no indica nada sobre el papel de esta "tabla antigua", pero Staub, que visitó España con motivo de la celebración en 1926 del XIV Congreso Geológico Internacional, hizo una interpretación general de la geología de la Península, incluyendo zonas como las Béticas o el Macizo Ibérico. Este último lo consideró formado por un núcleo arcaico bordeado a ambos lados por sendas fajas orogénicas caledonianas, que a su vez se hallarían bordeadas por sendas fajas hercinianas. Esta interpretación nace de la distribución de las rocas en el Macizo Ibérico. La franja que se extiende desde Galicia hasta el Guadarrama, que consta en buena parte de granitos, Staub (1926) la interpretó como un núcleo arcaico rígido. Bordeando este núcleo se encuentran a cada lado zonas formadas esencialmente por pizarras y cuarcitas del Paleozoico inferior, que en la interpretación de Staub serían sendas fajas orogénicas caledonianas. Finalmente, en las partes más septentrionales y más meridionales (Asturias oriental y sur de Portugal), se encuentran zonas formadas esencialmente por materiales del Paleozoico superior, interpretadas por Staub como dos fajas orogénicas hercinianas. Staub señala de todos modos que las dos fajas no son igualmente claras, y en cierto modo parece expresar ciertas dudas sobre la faja caledoniana e indica que "el cinturón caledoniano de las tierras marginales ha quedado incluido por los movimientos intracarbónicos". En la interpretación de Staub, las dos fajas caledonianas y hercínicas al norte y al sur del núcleo arcaico enlazarían entre sí por debajo de los terrenos meso-terciarios que forman la parte este de la Península, de modo que las fajas orogénicas de la península dibujarían una $S$, con el arco cantábrico, al norte, y otro arco con la concavidad opuesta, más al sur. La interpretación de Staub es aún recogida por Seidlitz (1931), si bien este autor consideraba que la parte precámbrica central del Macizo no habría actuado como un cuerpo rígido. En España, el trabajo de Staub debió causar un cierto impacto, ya que se publicó una traducción a cargo de A. Carbonell en la Real Academia de Córdoba, una versión simplificada en alemán en la Géologie de la Méditerranée Occidental, y una versión en catalán centrada en lo que decía de Cataluña, fue publicada por Candel Vila. No obstante, las interpretaciones de Staub también tuvieron algunas críticas en España, en una breve nota de Hernández Sampelayo (1928b), que de todos modos resulta bastante confusa. Con posterioridad, Llopis (1964), y más recientemente Martínez Catalán (2012), han vuelto a considerar la existencia de un arco en la zona centroibérica, con la concavidad al oeste, aunque con unos plateamintos distintos a los de Staub.

Frente a la interpretación de Staub, la escuela alemana de Stille postuló que toda la deformación y los granitos del macizo lbérico eran de edad herciniana, con lo cual dicho macizo sería un segmento de la cadena herciniana (o varisca) (Stille, 1927; Lotze, 1929) y a esta conclusión llegaron todos sus discípulos que trabajaron en el Macizo Ibérico (Carlé, 1945a,b; Schmidt Thomé, 1945). Por su parte Lotze (1945a) plantea la cuestión de la edad de los terrenos graníticos y de alto grado metamórfico en la parte central del Maci- 


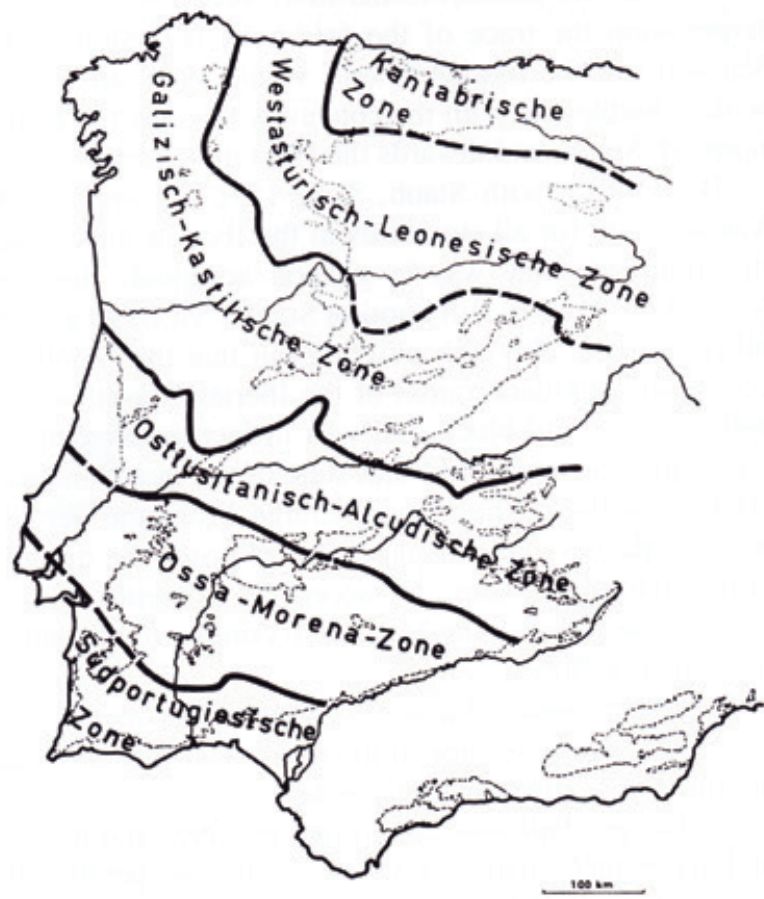

Figura 8. La zonación del Macizo Ibérico. Zonación establecida por Lotze (1945).

Figure 8. The zoning of the Iberian Massif established by Lotze (1945).

zo Ibérico y señala que un bloque "Arcaico" rígido debería cumplir tres condiciones: 1) que existiera un área arcaica extensa, 2) que la edad del metamorfismo y de los granitos fuera arcaica, y 3) que la edad de la orogénesis que afectara a estos materiales fuera pre-paleozoica, y que los sedimentos paleozoicos que los recubren no se hubieran deformado dúctilmente. Lotze señala que ninguna de estas tres condiciones se cumple, y que por tanto no existe un núcleo arcaico antiguo. Lotze, además, niega la existencia de una faja orogénica caledoniana.

La idea de un núcleo "Arcaico" rígido queda definitivamente descartada; no obstante, la interpretación de Staub, aunque incorrecta, se basa en un hecho real, que es la zonación que presenta la distribución de afloramientos paleozoicos en el Macizo lbérico y por tanto en el trazado de las estructuras, es decir de la faja orogénica.

\section{La zonación del Macizo lbérico}

Fue Calderón (1885) el que postuló por primera vez la existencia de una cierta zonación en la distribución de los materiales pre-mesozoicos del Macizo Ibérico, ya que este autor señaló que alrededor de una parte central antigua ("tabla antigua") se disponían fajas de materiales paleozoicos cada vez más modernos. Esta distribución ordenada de los materiales paleozoicos, que es en la que se basó Staub, quedó perfectamente clara al publicarse los primeros mapas de la península.

Basándose en las características de las diversas partes del hercínico en el Macizo Ibérico, Lotze (1945b) publicó un trabajo en el que dividía el mismo en varias zonas que de norte a sur eran: 1) Cantábrica, con potentes depósitos carboníferos, que representaría la parte marginal del "geosinclinal" paleozoico; 2) Asturoccidental-leonesa, con depósitos de gran espesor, que abarcan desde el Precámbrico al final del Silúrico; 3) Gallego-castellana, con predominio de granitos y rocas cristalinas, pero también con fajas de rocas paleozoicas de bajo grado; 4) Lusitana oriental-alcudiense, con gruesas series paleozoicas, desde la base del Cámbrico hasta la parte inferior del Devónico superior, con afloramientos extensos de esquistos y pizarras precámbricas, y con una importancia menor de las rocas plutónicas; 5) Ossa-Morena, muy variada en su composición, que incluye tanto al Precámbrico como a una variedad de rocas paleozoicas, desde el Cámbrico hasta el Carbonífero; 6) Surportuguesa, con una gruesa serie carbonífera, en facies culm, y que formaría el dominio marginal de la rama sur del orógeno hercínico (fig. 8).

Considerando la estructura global del Macizo, Lotze (1929), como toda la escuela alemana, lo considera un segmento de la cadena hercínica y distingue en ella dos ramas con vergencias opuestas, de las cuales sus futuras zonas Cantábrica y Sur-portuguesa, forman las partes frontales. De todos modos, las partes más centrales del Macizo son de adscripción más dudosa, y Lotze (1929) coloca el límite entre ambas ramas demasiado desplazado hacia el norte (fig. 9).

La zonación establecida por Lotze se ha mantenido con pocos cambios hasta la actualidad, pero las dos zonas centrales quedan menos definidas, por lo que con motivo de la preparación del Mapa Tectónico de la Península las zonas 3 y 4 de Lotze se agruparon en una única Zona Centroibérica, dado que ambas zonas se individualizan mal (Julivert, 1983) (fig. 10).

\section{El arco cantábrico y sus enlaces}

La existencia de una forma arqueada de las estructuras en Asturias puede leerse ya en el mapa de Schulz y por tanto también en el mapa de España a escala 1:400.000, pero no se había tratado explicitamente la cuestión de sus enlaces con el resto de Europa. Al arco cantábrico se hace una clara referencia en el libro de Suess Das Antliz der Erde (1885-1909), comparándolo con el arco de Gibraltar, aunque no se plantea la cuestión de sus enlaces. Suess interpreta todos los macizos antiguos de la Europa central y occidental, incluyendo 


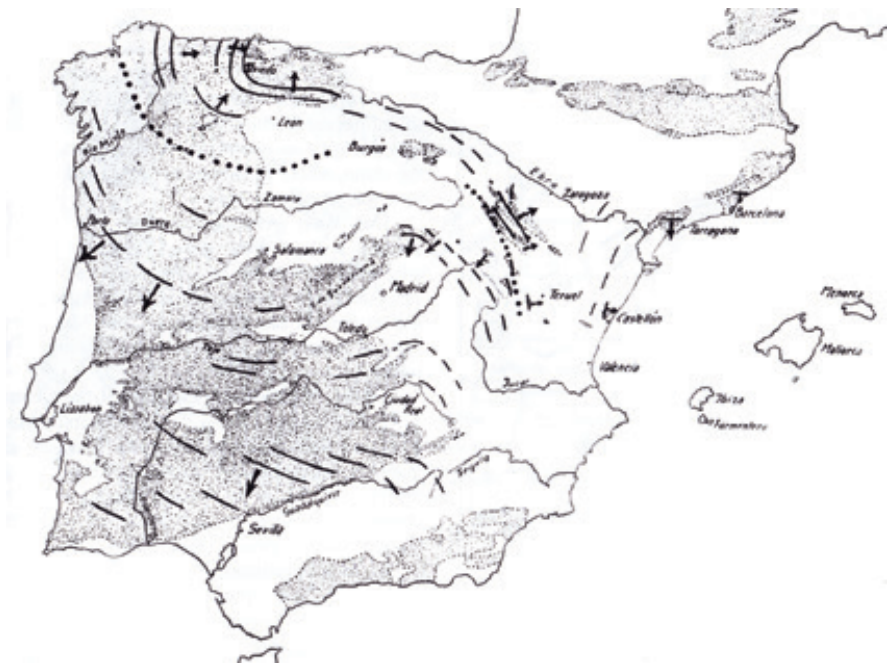

Figura 9. Distribución de las vergencias en el Macizo Ibérico, según Lotze (1945).

Figure 9. Distribution of the inclines in the Iberian Massif, according to Lotze (1945).

el Macizo Ibérico, como partes de la cadena herciniana, en la que distinguía tres segmentos: varisco (en Europa Central), hercínico (en Francia) e ibérico. Los segmentos varisco y hercínico con direcciones WSW y WNW respectivamente eran fáciles de enlazar, pero el enlace con el segmento ibérico era más problemático, ya que entre él y el segmento armoricano se interponía el Golfo de Vizcaya, pero Suess no se manifiesta sobre esta cuestión, aunque autores posteriores dan por sentado el enlace con las estructuras de Bretaña (Staub, 1926). A partir de Kossmat (1927), a pesar del problema del enlace, el Macizo lbérico se consideraba una parte de la cadena hercínica, uniendo la parte europea de dicha cadena con la parte africana.

Fue muchos años más tarde cuando Lotze (1963) dibujó claramente el enlace entre las estructuras ibéricas, las bretonas y las del SW de Inglaterra mediante un arco a través del Golfo de Vizcaya (fig. 11). El enlace parecía lógico, pero presentaba un gran problema y es que su trazado se hacía por zonas oceánicas profundas y no se podía suponer que masas continentales se hubieran hundido, lo cual era contrario a los principios de la isostasia.

Carey, ya en 1958, basándose en la deriva continental, había relacionado las estructuras ibéricas y armoricanas, pensando en una rotación de la península que la separara de Bretaña y en que esta rotación y consiguiente apertura del Golfo serían compensadas por el cierre de los Pirineos (fig. 12). Más tarde, la evidencia de la apertura del Golfo de Vizcaya vino con la tectónica de placas. Las anomalías magnéticas atlánticas, con la anomalía 34 penetrando en el Golfo de

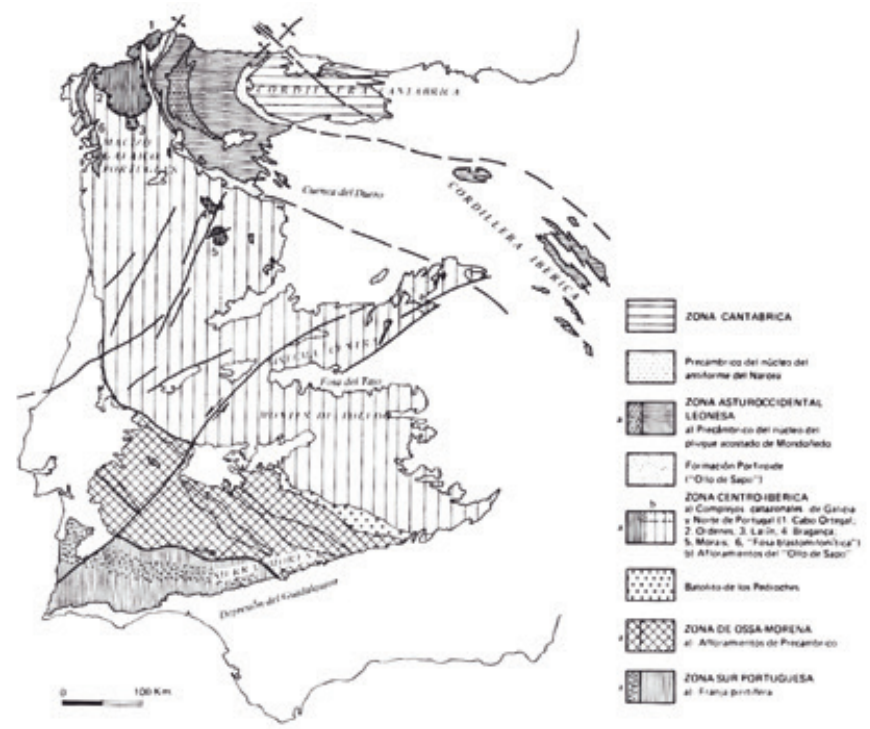

Figura 10. La zonación del Macizo Ibérico (según Julivert, 1983). Figure 10. The zoning of the Iberian Massif according to Julivert, (1983).

Vizcaya, ponen de manifiesto que el Golfo de Vizcaya se ha abierto, pero la apertura debió producirse por desplazamiento y rotación de la península a lo largo de una fractura, movimiento que separaría España de Bretaña y abriría el Golfo de Vizcaya (Le Pichon et al., 1970) (fig. 13).

\section{Los progresos de la cartografía: los trabajos de la Uni- versidad de Oviedo, el IGME y la escuela de Leiden (décadas de los 50 y 60) en la Zona Cantábrica}

Durante la década de los 50 y principios de los 60 se hizo un gran progreso en el conocimiento de la Zona Cantábrica gracias principalmente al incipiente grupo de la Universidad de Oviedo, dirigido por Llopis, que trabajó en la vertiente de Asturias, y a la escuela de Leiden, dirigida por De Sitter, que trabajó en la vertiente leonesa. Durante este periodo se realizaron cartografías detalladas, que permitieron sentar las bases para ulteriores interpretaciones. Aquí no se pretende dar una relación completa de las cartografías realizadas, sino tan sólo en la medida en que estas fueron la base para el progreso de la interpretación de la tectónica de la Cordillera. Una relación más exhaustiva de las cartografías realizadas en Asturias puede encontrarse en Truyols y Marcos (1978).

El grupo de la Universidad de Oviedo, poco numeroso (Llopis sólo, primero, Llopis y Julivert entre octubre de 1952 y junio de 1956, Llopis y J.A. Martínez desde 1957 hasta la creación de los estudios de Geología), realizó no obstante una labor bastante extensa. 


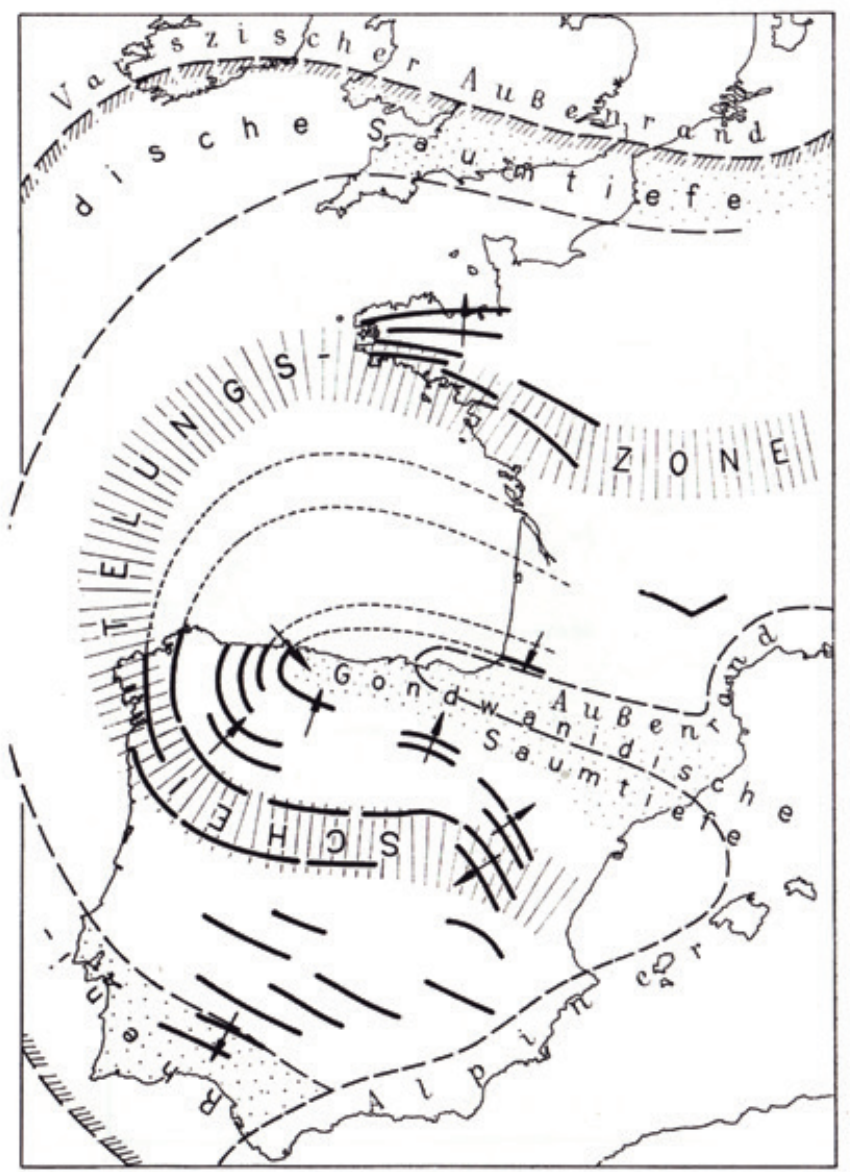

Figura 11. El enlace del Macizo Ibérico y el Macizo Armoricano, a través del Golfo de Vizcaya, según Lotze (1963).

Figure 11. The connection of the Iberian Massif and the Armorican Massif via the the Bay of Biscay.

Durante el periodo que permaneció sólo en Oviedo, Llopis publicó sus dos mapas, uno de los alrededores de Oviedo y el otro de la Sierra de la Coruxera, la Mostayal y el Monsacro (Llopis, 1950a, 1950b). Llopis (1961) publicó también, más tarde, un mapa del "Batolito de Boal", donde realizó estudios de minería.

Julivert hizo su tesis doctoral en la región de los ríos Sella y Ponga (Julivert, 1960), que es la parte oriental de lo que ahora se conoce como manto del Ponga. La tesis contenía un mapa y una estratigrafía correctas, pero las estructuras cabalgantes no estaban bien interpretadas. En aquella época había en España una desconfianza hacia los mantos de corrimiento y había causado un gran impacto un trabajo de Lotze sobre los "klippes autóctonos" del Pirineo, interpretando determinadas estructuras como extrusiones ${ }^{1}$.

${ }^{1}$ En mi tesis, siguiendo las ideas entonces predominantes en España, y contra toda evidencia, interpreté la estructura

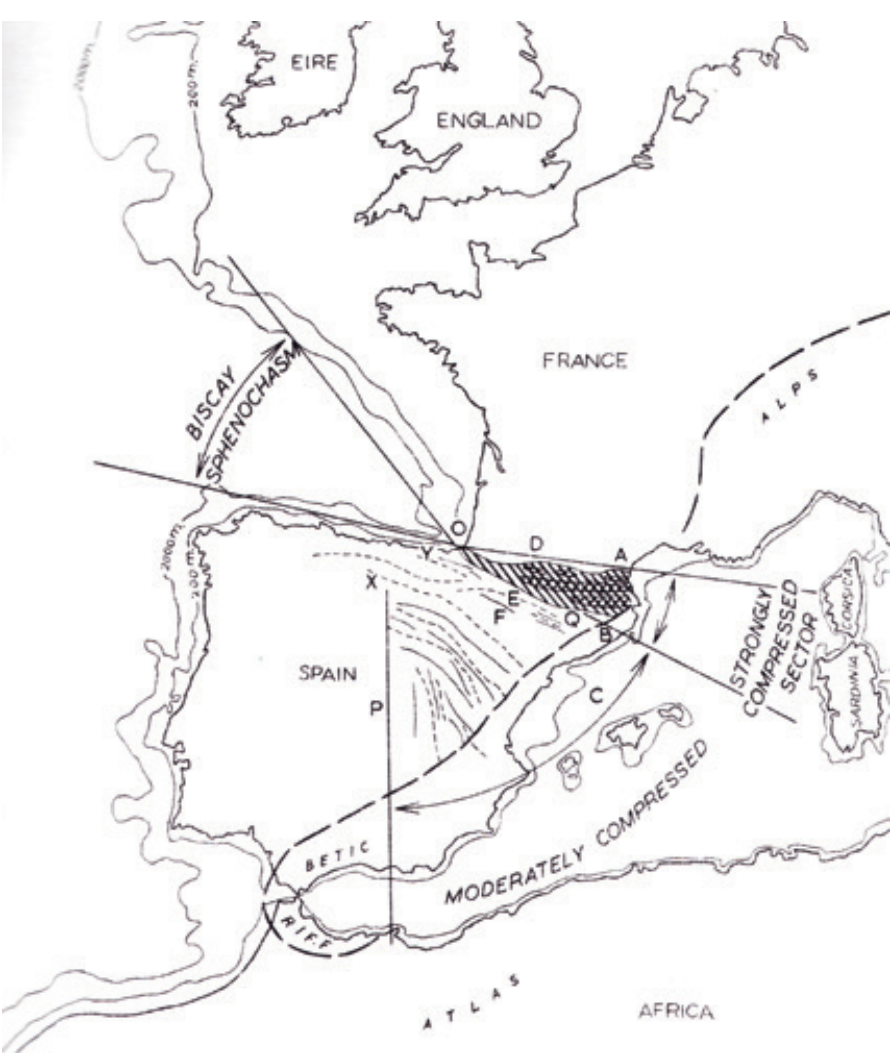

Figura 12. Interpretación de Carey (1958) de la apertura del Golfo de Vizcaya mediante una rotación de la Península con la consiguiente apertura del Golfo compensada por la compresión y plegamiento pirenaicos (sphenochasm, en la nomenclatura de Carey).

Figure 12. Carey's interpretation (1958) of the opening of the Bay of Biscay due to the rotation of the peninsula that was compensated for by the comression and folding in the Pyrenee mountain belt ("sphenochasm", in Carey's nomenclature).

J. A. Martínez hizo su tesis inmediatamente al este de la de Julivert, aunque quedó alguna zona en blanco entre ambas, y básicamente abarcó las dos escamas de Rioseco y Laviana (Martínez Álvarez, 1962). Aunque tampoco interpretó su estructura cabalgante, la estratigrafía y la cartografía eran de todos modos correctas, de modo que, al realizarse más tarde el análisis de conjunto de la Zona Cantábrica, fue fácil reinterpretarlas.

Otras cartografías que se hicieron en la parte asturiana de la cadena fueron el trabajo de Almela (1952) sobre el Carbonífero de La Robla, el mapa de Almela

desde un punto de vista autoctonista, aunque debo añadir que ninguno de los miembros de mi tribunal de tesis me sugirió que tal vez cabían otras interpretaciones. Durante mi estancia en Colombia entré en contacto con la bibliografía americana y con la geología apalachiense, y al regresar a España, como mi cartografía era correcta, pude reinterpretar fácilmente la estructura (Julivert, 1971). 


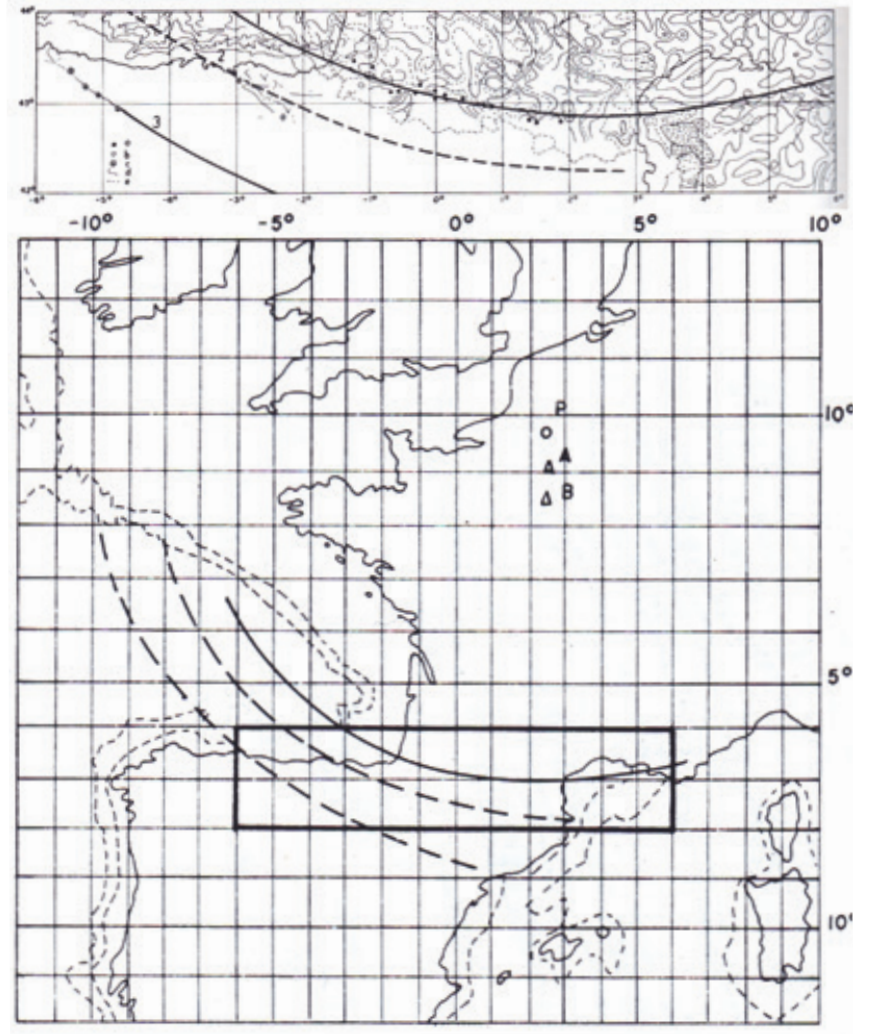

Figura 13. La apertura del Golfo de Vizcaya producida por la rotación de la Península que se mueve según una falla de strike-slip, según Le Pichon y Sibuet (1970). Estos autores consideran tres posibilidades respecto a la situación de esta falla, inclinándose por hacerla coincidir con la falla norpirenaica.

Figure 13. The opening of the Bay of Biscay produced by the rotation of the peninsula following a strike-slip fault, according to $\mathrm{Le} \mathrm{Pi-}$ chon and Sibuet (1970). These authors consider that there are three possibilities for the location of this fault, favouring that which coincides with the one in the northern Pyrenees.

y Ríos sobre la región de Riosa y Proaza (1955), que en parte se superpone al de Llopis, la hoja de La Plaza (Teverga) por García Fuente (1959), en la que es de señalar que este autor interpretó correctamente los cabalgamientos de lo que hoy se llaman el Manto de Somiedo y el de La Sobia, aunque el primero había sido señalado ya por Gómez de Llarena y Rodríguez Arango (1948), y un mapa del Aramo y zonas vecinas (Julivert, 1963). Otros mapas que se publicaron en este periodo son menos significativos. Almela y Ríos (1962) publicaron también un trabajo sobre los terrenos hulleros por debajo del Mesozoico de la costa cantábrica, tema que había interesado ya a Adaro (1914).

A diferencia del grupo de Oviedo, el de Leiden contó con un buen número de personas que prepararon sus tesis en la vertiente sur de la Zona Cantábrica, realizando un trabajo sistemático que cubrió la totalidad de dicha vertiente en las provincias de León, Palencia y Cantabria. Entre las publicaciones realizadas cabe citar las siguientes, en cuya lista in- cluyo algunas más tardías a las fechas que se están considerando, para colocar juntas las de la citada escuela: la publicación de Nederlof y De Sitter (1956) sobre la cuenca carbonífera del Pisuerga, la de $\mathrm{Ne}$ derlof (1959) sobre el Pisuerga, la de De Sitter (1957) sobre el Precámbrico de la Cordillera Cantábrica, la de Koopmans (1962) sobre la región de Valsurbio, la de Helmig (1965) sobre Valderrueda, Ocejo, Tejerina y Sabero, la de Frets (1965) sobre el Pisuerga, de Kanis (1956) sobre la región de la Sierra del Brezo, la de Rupke (1965) en la región del Esla, la de Sjerp (1967) sobre la región de San Isidro y el Porma, la de Evers (1968) sobre la región del Bernesga, la de Brower (1968) sobre el Devónico, la de Boshma (1968) sobre la vertiente sur de la cordillera, la de van den Bosch (1969) sobre la región de los valles del Luna y el Sil, la de van Staalduinen (1973) sobre el área de los ríos Luna y Torío, la de Maas (1974) sobre la región de la Liébana, la de Savage (1979) sobre la zona de Curavacas y Lechada y la de Meer Mohr (1983) sobre el Paleozoico Inferior. Todos estos trabajos contenían una buena cartografía, lo que permitió llegar a un buen conocimiento de la parte leonesa-palentina de la Cordillera Cantábrica, y permitió a De Sitter (1962) presentar un mapa de conjunto acompañado de una breve descripción. De Sitter (1960) publicó también un trabajo sobre el "cross-folding" en la Cordillera Cantábrica.

La escuela de Leiden no se limitó a estudios regionales, con una buena cartografía, sino que, una vez cartografiada la región, abarcó temas sedimentológicos y paleontológicos que, por tratarse de temas no relacionados directamente con la estructura del NW peninsular, no van a ser citados aquí. Sobre la labor de la Universidad de Leiden en la Cordillera cantábrica ha tratado recientemente Winkler Prins (2013).

\section{Del reconocimiento de los primeros cabalgamientos hasta una interpretación global de la Zona Cantábri- ca. La cuestión de la "León Line"}

En cierto modo el corte puntual de Mallada, ya citado, señala un Cámbrico cabalgante, aunque piensa que la estructura se forma por rotación de fallas verticales. Pero los primeros en reconocer la existencia de un manto en la Cordillera Cantábrica fueron Gómez de Llarena y Rodríguez Arango (1948), que señalaron el cabalgamiento del Cámbrico sobre el Carbonífero en la vertiente leonesa, al sur de Puerto Ventana, aunque el trabajo está centrado esencialmente en el conjunto cabalgado (fig. 14). Refiriéndose a este cabalgamiento, los citados autores identifican la base del manto con "la caliza nodulosa roja mesocámbrica"y señalan que tan- 


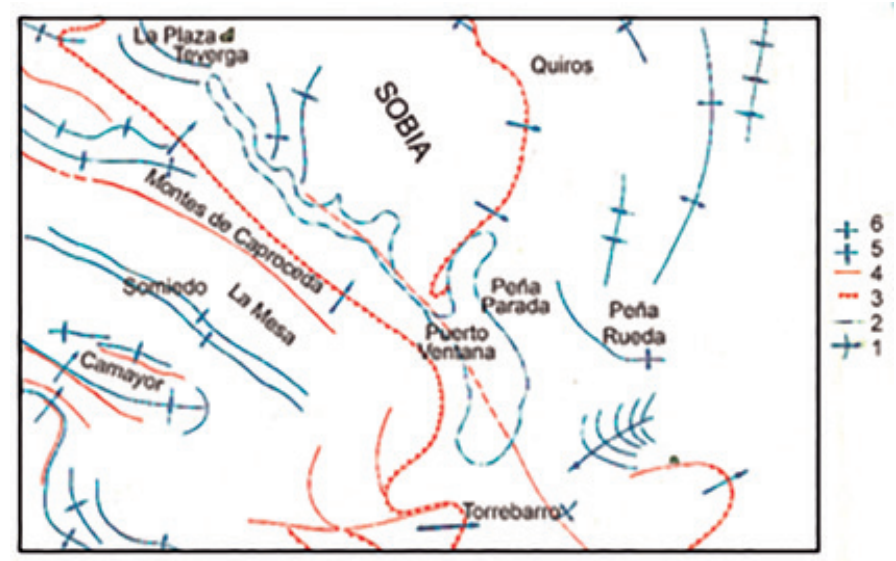

Figura 14. Esquema estructural de García Fuente (1959) del área de Somiedo y La Sobia en el que se marcan perfectamente los cabalgamientos de estas dos unidades. 1: Vergencia. 2: Discordancia. 3: Cabalgamiento. 4: Falla. 5: Sinclinal. 6: Anticlinal.

Figure 14. Structural diagram by García Fuente (1959) of the Somiedo and La Sobia areas in which the overthrust of these two areas can be clearly identified. 1: Vergence. 2: Disconformity 3: Overthrust 4: Fault 5: Syncline 6: Anticline.

to las capas de la base del manto como las de su sustrato se disponen paralelamente, de modo que "de no existir fósiles haría creer que la sucesión estratigráfica es normal". El trabajo incluye un mapa esquemático del conjunto cabalgado del sector al sur de Puerto Ventana.

Posteriormente, se reconocieron diversas estructuras cabalgantes por parte de García Fuente (1959), De Sitter (1959) y Compte (1959). García Fuente realizó la hoja de La Plaza (Teverga) del Mapa Geológico Nacional a escala 1:50.000 y cartografió los cabalgamientos de Somiedo y La Sobia, pero se limitó a trazar el frente cabalgante sin plantearse otras preguntas sobre ellos. De Sitter (1959) publicó un trabajo sobre el Manto del Esla (fig. 15) que apareció también el mismo año que la tesis de Compte (1959), que igualmente dibuja el manto del Esla (fig. 16) y otras escamas, aunque Compte debió conocer la estructura desde mucho antes, ya que su tesis tardó mucho en publicarse por causa de las guerras. Como es natural, todos los trabajos de la escuela de Leiden dibujan los frentes cabalgantes de las diversas estructuras, y en un trabajo más sintético De Sitter da unos cortes generales de la rama leonesa del orógeno (fig. 17) y dibuja las estructuras cabalgantes (De Sitter, 1965a, 1965b). En un esquema que incluye áreas de la vertiente norte de la cordillera, De Sitter (1965b) dibujó incluso como cabalgantes los frentes de las escamas de Laviana y Rioseco, región que conocía sólo por los mapas de Martínez (1962), aunque no se atrevió a interpretar el Manto del Ponga, de trazado mucho más complejo y de cartografía aún incompleta. No obstante, a pesar del reconocimiento de la estructura en mantos, en ninguno de estos tra- bajos se analizan sus características. La preocupación principal es la dirección del movimiento o su enrraizamiento.

De regreso de Colombia, y familiarizado ya con la geología apalachiense, Julivert hizo varias salidas geológicas para completar unos vacíos que habían quedado entre su tesis y la de J.A. Martínez y dar una interpretación completa del área. Como resultado se localizaron dos ventanas tectónicas, la de Río Color y la de Río Monasterio (Julivert 1965, 1967a, 1967b), con lo cual, la estructura del Ponga quedaba establecida como un gran manto de corrimiento, el mayor de los mantos cantábricos (Julivert 1965) (figs. 18 y 19). Sus características son las de un manto de despegue, formando la base del mismo, y en general de todos los mantos y escamas cantábricos, la base de la Formación Láncara, de edad cámbrica. Sobre el manto del Ponga, Julivert publicó además dos trabajos, que incluían una cartografía detallada de la región de su tesis más la de las nuevas áreas estudiadas (Julivert 1967a, 1967b). La cartografía de la prolongación de estas estructuras hacia el norte quedó completada con los estudios de Marcos (1967) y Pello (1967).

Un tema recurrente en los estudios holandeses fue el de la "León Line" y su significado. Para De Sitter (1962) la "León Line" era una estructura que separaba dos dominios, que denominaba "leónides" y "astúrides" que tendrían edades de deformación diferentes. En las leónides, las estructuras Ilevarían dirección E-W, y en las astúrides N-S. A esta interpretación se oponía no sólo la cartografía antigua existente, que si bien muy rudimentariamente, dibujaba el arco, y la hoja de La Plaza realizada por García Fuente, de la que ya se ha tratado, sino también la forma arqueada de las estructuras, reconocida ya por Suess, y la multitud de arcos existentes en los orógenos europeos alpídicos. Aunque la interpretación en cuanto a las edades de las estructuras es completamente diferente, no deja de llamar la atención la semejanza con la interpretación de Termier, que consideraba diferentes las edades de las estructuras N-S (estefanienses) del arco y las estructuras E-W (alpídicas). Nuevos estudios realizados sobre el área de Somiedo-Proaza (Soler, 1967; Julivert et al., 1968; Marcos 1968) pusieron de manifiesto, una vez más, que las estructuras E-W de la rama leonesa giraban para describir el arco asturiano, en continuidad con las N-S o NW-SE de la parte norte.

Este giro de las estructuras, evidente hacia el oeste, no se observa claramente hacia el este, donde la "León Line" fue definida, y donde las estructuras asturianas parecen chocar con las leonesas. Ello es debido probablemente a que se trata del núcleo del arco, donde hay problemas de espacio, por lo que se desarrollan estructuras de acomodación que faltan 


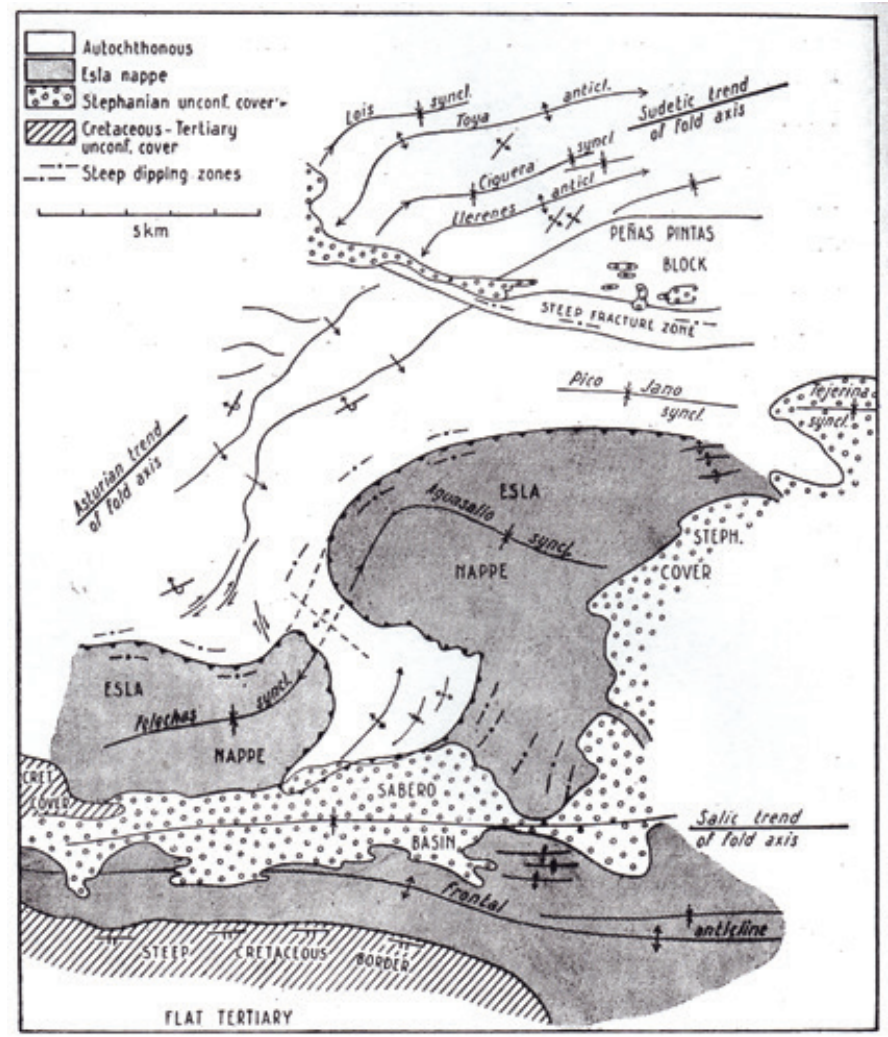

Figura 15. El manto del Esla según de Sitter (1959).

Figure 15. The Esla nappe, according to Sitter (1959).

más al oeste. Es por esto probablemente que el tema de la "León Line" aparece aún de vez en cuando en la literatura geológica (por ejemplo, Alonso et al., 2009), pero probablemente, mientras no haya buenos datos de subsuelo, el detalle del significado de la "Leon Line" en esta parte del arco no podrá ser conocido.

Entre tanto, la cartografía iba cerrando los espacios en blanco que quedaban aún en la Zona Cantábrica o dando mayores precisiones a su conocimiento (Marcos 1967, 1968; Julivert, 1976; Rodríguez Fernández, 1978; Truyols y Julivert, 1976; Lobato, 1977). A la labor de completar las zonas en blanco o no suficientemente cartografiadas que quedaban contribuyó más tarde el plan MAGNA, del nuevo mapa geológico a escala 1:50.000 del IGME, ya que, al tratarse de una cuadrícula, no dejaba áreas blancas de por medio. De todos modos, ya en la década de los 70 pudo publicarse una interpretación estructural de la Zona Cantábrica completa, como un "fold and thrust belt" (fig. 20), formado por una serie de escamas y mantos de despegue, despegados en general por la base de la Formación Láncara (Cámbrico), y que hacia el noroeste pasaban a una estructura con predominio de pliegues (Julivert, 1971). Se vió además que las estructuras que describen el arco están afectadas por una serie de pliegues transversales (Juliverty Marcos, 1973), lo que da lugar a unas estructuras de "cross folding" y se definió la zona del Antiforme del Narcea, límite entre las zonas Asturoccidental-leonesa y Cantábrica, es decir entre la zona de cabalgamientos más profundos que hacia la parte frontal pasaba a dar lugar a la superficie general de despegue.

\section{La base de los mantos y escamas}

Los rasgos generales y la distribución de las diferentes formaciones cantábricas eran conocidos como consecuencia del progreso de la cartografía. Se sabía, por ejemplo, ya desde los tiempos de Adaro, que el Devónico desaparecía hacia el interior de Arco, y que al este de la Cuenca Carbonífera Central las calizas carboníferas se apoyaban directamente sobre las cuarcitas ordovícicas, aunque este hecho quedó matizado por el descubrimiento de una faja de pizarras del Ordovícico medio, por encima de la cuarcita del Arenig, en la región del Sueve y en la escama de Laviana (Pello y Philippot, 1967; Julivert, Marcos, Philippot y Henry, 1968). Otro descubrimiento estratigráfico, de implicación tectónica, fue el reconocer que el Cámbrico, representado por la Formación Láncara, que había pasado desapercibido en grandes áreas, estaba presente también en la Asturias oriental (Zamarreño, 1972; Zamarreño y Julivert, 1967) y cuya fauna estudió Sdzuy (1967). Se vió que las calizas cámbricas formaban la base de todos los mantos y escamas, tal como habían reconocido por primera vez Gómez de Llarena y Rodríguez Arango (1948) en Somiedo. Años más tarde, pequeños afloramientos cámbricos se encontraron incluso en áreas más orientales (Picos de Europa: Marquínez, 1978; Martínez García, 1978, 1981; Farias, 1982; Martínez García y Rodríguez Fernández, 1984).

\section{El antiforme del Narcea y las zonas más internas del orógeno (la zona Asturoccidental-leonesa)}

La estructura en mantos de despegue termina hacia el oeste en el Antiforme del Narcea a lo largo del cual hay un extenso afloramiento del Precámbrico describiendo el arco asturiano. La existencia del área precámbrica, era ya conocida, pero su modo de presentarse, en posición cabalgante se precisa en los años 70 (Julivert y Marcos, 1970; Julivert, 1971; Pérez Estaún, 1971). Este antiforme queda definido como el límite oeste de las estructuras de despegue cantábricas y además a partir de él se produce un cambio en las condiciones de deformación, como se verá a continuación.

Al oeste del Antiforme del Narcea, que es el límite occidental de la Zona Cantábrica, la geología cambia en 


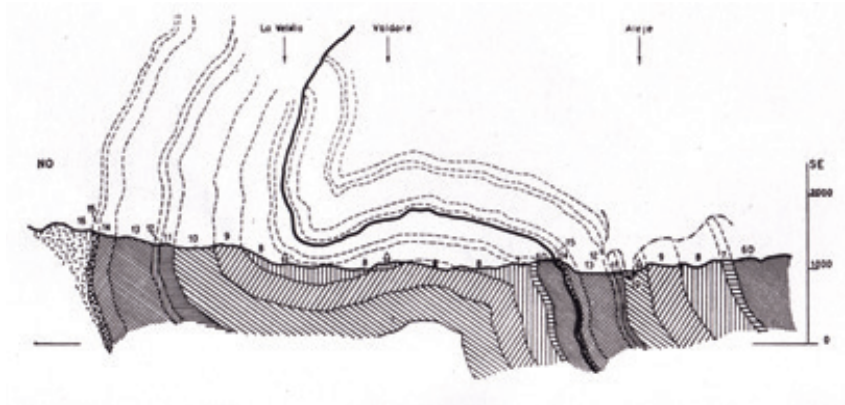

Figura 16. Corte del manto del Esla según Compte (1959). Aunque esta publicación es de fecha muy tardía debido a las guerras, Compte debió conocer este manto ya en los años 30.

Figure 16. Cross-section of the Esla nappe according to Compte (1959). Although the publication of this paper was very delayed due to the Spanish Civil War, Compte must have identified this nappe in the 1930s.

gran medida: las pizarras ordovícicas, por encima de la Cuarcita Armoricana (Arenig; Floiense en la nomenclatura actual) cobran gran espesor, el Devónico y el Carbonífero ante-estefaniense faltan, desaparece la tectónica en mantos de despegue y en su lugar hay grandes pliegues tumbados. Existe también algún pequeño macizo granítico algo mayor hacia el oeste, aparece un metamorfismo, creciente de este a oeste, y la deformación va asociada a la generación de foliaciones.

Esta región había permanecido poco conocida, ya que existían sobre ella tan sólo algunos datos estratigráficos de Barrois (1882) y de Lotze (1961), que, con sus síntesis del Cámbrico, presentó el cuadro general del mismo en toda España. Pueden citarse además los trabajos de Hernández Sampelayo sobre los yacimientos de hierro (en Adaro y Junquera, 1916), referidos simplemente al estudio este tipo de yacimientos, algún que otro trabajo sobre cuestiones puntuales (Llopis, 1961; Suárez y Suárez, 1970; entre otros), o algunos trabajos alemanes (Farber y Jaritz, 1964; Nollau, 1965, 1968; Poll, 1970), sin que ninguna de estas publicaciones diera una imagen de la estructura general del área.

El primer dato estructural importante lo dieron los trabajos de Walter $(1965,1966 a, 1966 b, 1968)$, que describió el manto de Mondoñedo, presentando un mapa esquemático y un corte del mismo (figs. 21 y 22), en los que aparece el manto como formado por un apilamiento de pliegues acostados y formando todo el conjunto un suave sinforme, con su eje levantándose hacia el norte. Aparece, pues, una estructura completamente diferente a las de los mantos cantábricos. La Zona Asturoccidental-leonesa aparece no sólo bien individualizada estratigráficamente, sino también estructuralmente, como mostrarán también las estructuras menores y el metamorfismo.
Posteriormente, con la llegada de la escuela de Mattauer, de Montpellier, se realizan estudios que abarcaban toda la Zona Asturoccidental-leonesa. Estos estudios fueron realizados por Matte, en el dominio estructural, y por Capdevila, en el dominio del metamorfismo y los granitos. Los trabajos de Matte (1967a, 1967b, 1968, 1969), que culminaron con su tesis doctoral, pusieron de manifiesto la existencia de otro manto, además del de Mondoñedo (fig. 23), descrito ya por Walter, el manto del Caurel (fig. 24), ambos formados por grandes pliegues tumbados. Matte da también un corte general a través de la Zona Asturoccidental-leonesa (fig. 25). Aunque Walter (1966a, b) cita ya la presencia de una esquistosidad en el Manto de Mondoñedo, fue con la la tesis de Matte que se tomaron ampliamente en consideración las foliaciones tectónicas, lo que le llevó a distinguir entre una primera fase de deformación, asociada a la formación de los grandes matos y con desarrollo de un "slaty cleavage", y una segunda fase de plegamiento, deformando las primeras estructuras, y asociada a una crenulación (crenulation cleavage), a todo lo cual sucedía una generación de kink-bands (Matte, 1969). Matte, en colaboración con Ribeiro hizo también un estudio sobre la forma y orientación del elipsoide de deformación en el arco hercínico, en Galicia, que fue el primer estudio de esta clase (Matte y Ribeiro, 1975).

Los trabajos de Capdevila $(1967,1969)$ destinados también a preparar su tesis doctoral, permitieron establecer una zonación metamórfica a través de la Zona Asturoccidental-leonesa, con metamorfismo creciente de este a oeste. Capdevila estudió también las intrusiones graníticas, sobre las que realizó diversas publicaciones (Capdevila, 1967, 1969, 1976; Capdevila y Floor, 1970; Capdevila y Vialette, 1965; Capdevila, Corretgé y Floor, 1973) y reconoció una serie de episodios en las intrusiones ígneas, distinguiendo entre unas granodioritas precoces, unos granitos de dos micas y unas granodioritas tardías. Los trabajos citados son de naturaleza petrográfica, pero se hace referencia a ellos aquí porque junto con los estudios estructurales de Walter y Matte permiten tener por primera vez una visión general de la Zona Asturoccidental-leonesa.

Los trabajos de Matte y Capdevila abarcaban un área muy grande (toda la Zona Asturoccidental-leonesa en el caso de Matte), y por tanto no excluían la posibilidad de realizar estudios más detallados, y en este sentido se realizaron los trabajos de Marcos y Perez Estaún, el primero de ellos sobre la región de Los Oscos (Marcos, 1973) y el segundo (Pérez Estaún, 1978) sobre la rama sur del arco, en la Zona Asturoccidental-leonesa, y los de Bastida y Pulgar (1978) y Martínez Catalán $(1980,1981)$, sobre el manto de Mondoñedo. Además, se reconoció la existencia de una serie tur- 


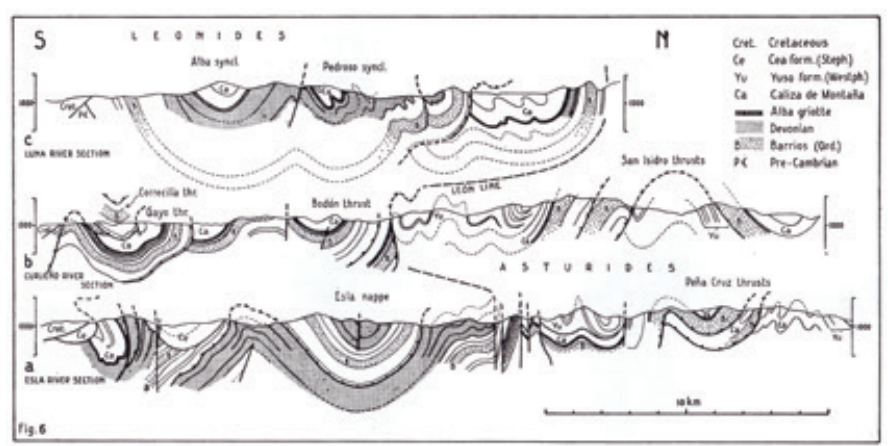

Figura 17. Cortes de de Sitter (1965b) de la vertiente leonesa de la Cordillera Cantábrica.

Figure 17. Cross-sections by Sitter of the Leonese slope of the Cordillera Cantábrica.

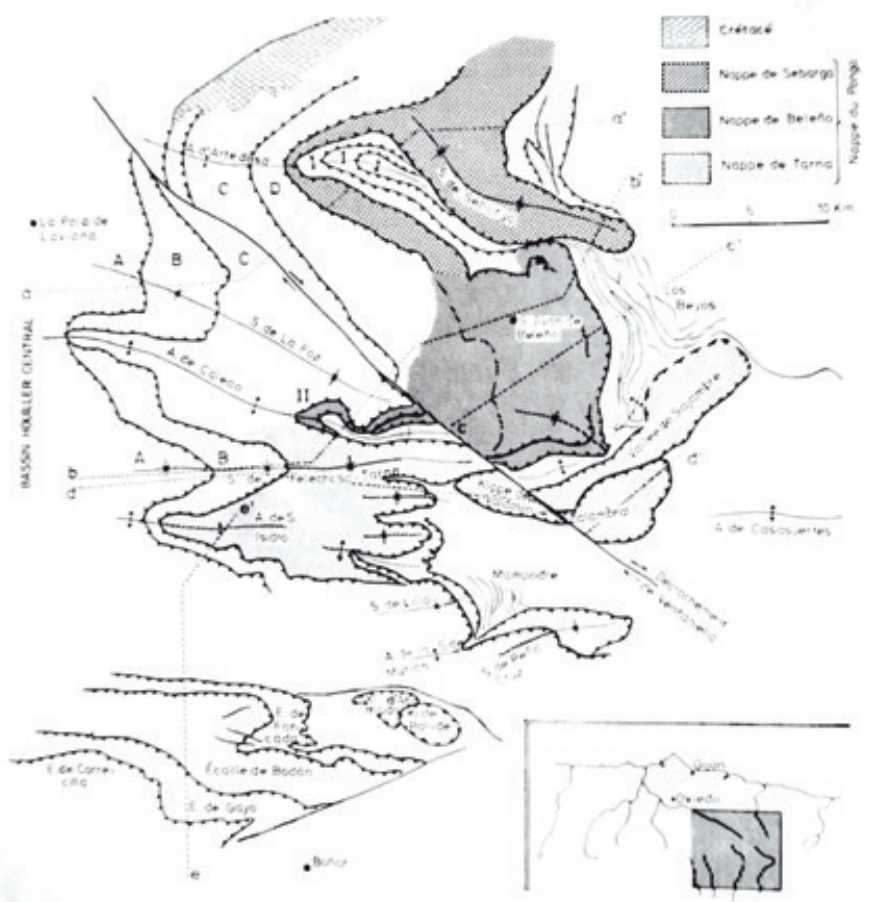

Figura 18. Esquema estructural del manto del Ponga (Julivert, 1965). Figure 18. Structural diagram of the Ponga nappe (Julivert, 1965).

bidítica ordovícica (Marcos, 1970). Todos estos trabajos hicieron posible una interpretación general de la cuenca ordovícica (Julivert, Marcos y Truyols 1972).

\section{Galicia y la cuestión de los macizos con rocas básicas y ultrabásicas}

Galicia es una región con gran abundancia de granitoides y con metamorfismo de alto grado y esto, junto con la presencia de los complejos de rocas básicas y ultrabásicas, ha sido la causa de que se hayan realiza-

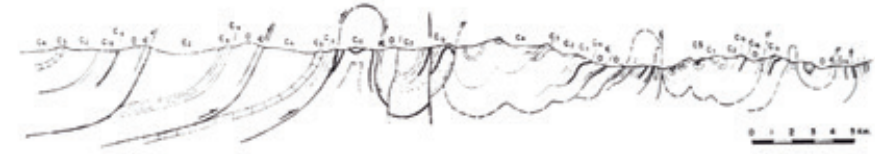

Figura 19. Corte del Manto de Ponga y de las escamas al E de la cuenca Carbonífera Central (Julivert, 1971).

Figure 19. Cross-section of the Ponga nappe and the tectonic slices to the east of the central Carboniferous basin.

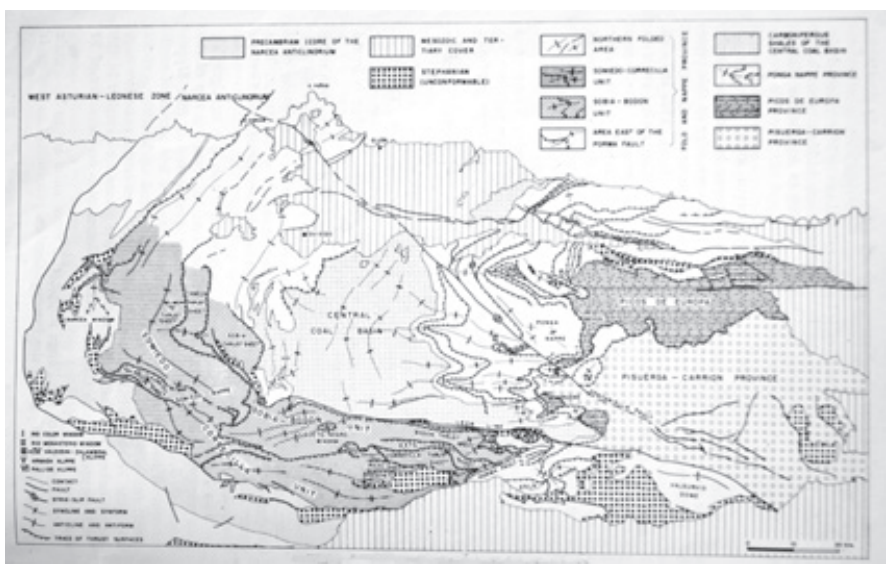

Figura 20. Esquema estructural de la Zona Cantábrica (Julivert, 1971).

Figure 20. Structural diagram of the Cantabrian Zone (Julivert, 1971).

do muchos estudios petrográficos en la región. Aquí se citará este aspecto sólo someramente, ya que el objeto básico de este estudio histórico es poner de manifiesto como se ha ido conociendo la estructura de este sector de la Cordillera Hercínica. Aun así, al igual que se ha hecho anteriormente, por las connotaciones que el conocimiento regional tiene sobre la interpretación de la estructura, se hará referencia, si bien más marginalmente, a una multitud de trabajos sobre tópicos diversos. De todos modos, en esta parte, se centrará la atención en los macizos con rocas básicas y ultrabásicas y en su interpretación tectónica, que desde el punto de vista estructural han sido objeto de debate.

Los primeros trabajos sobre Galicia fueron de tipo petrográfico, ya que estos, en su aspecto descriptivo eran los únicos posibles en la época, o bien unos primeros tanteos cartográficos. En este sentido son de señalar las publicaciones ya citadas de Schulz (1835), que realizó el primer mapa geológico de Galicia y las de Macpherson (1883-84, 1886), así como los mapas de la serie 1:400.000 ( $2^{\mathrm{a}}$ edic. 1907, bajo la dirección de Cortázar), que se limitan a determinar más o menos la extensión que ocupan en superficie los diferentes tipos de rocas. 


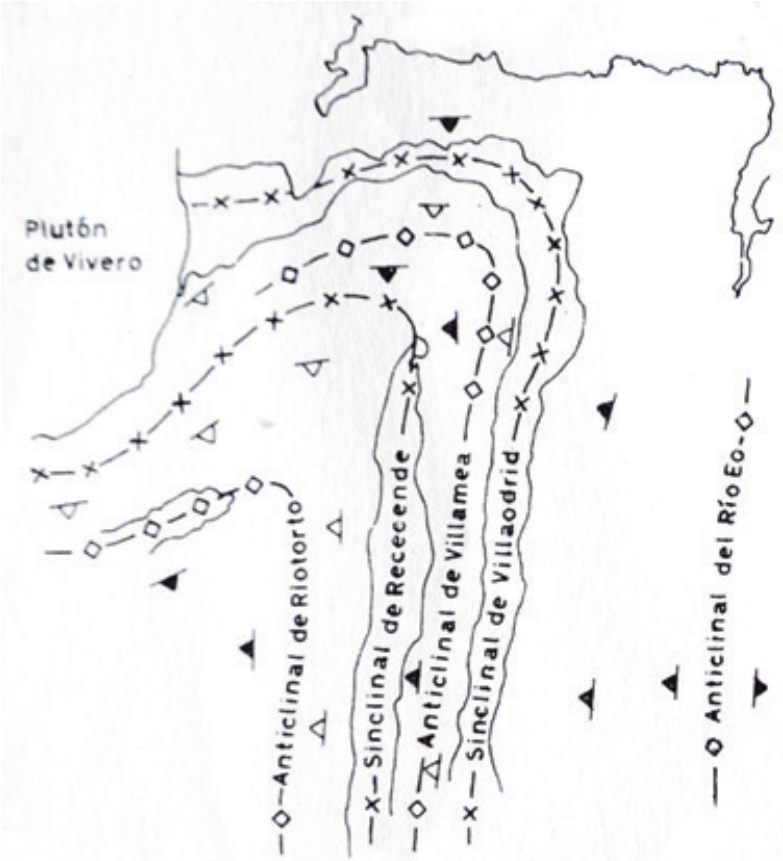

Figura 21. Esquema del Manto de Mondoñedo, según Walter (1966). Figure 21. Diagram of the Mondoñedo nappe, according to Walter (1966).

Más tardiamente, Hernández Sampelayo (1922) hizo una publicación de carácter minero sobre los hierros de Galicia. En los años cuarenta aparecieron varios trabajos alemanes sobre la Zona Centroibérica, como ya se ha indicado al tratar de la cuestión del núcleo granítico-metamórfico del Macizo Ibérico. Aquí es de citar el trabajo de Carlé (1945a, 1945 b) en el que, además de las observaciones sobre los granitos, se señalan ya los complejos con rocas básicas y ultrabásicas y se dibujan en un mapa esquemático sobre Galicia. Más tarde aparecieron varios trabajos y mapas de Parga (1956, 1960, 1963, 1966), de Parga y López de Azcona (1965), de Parga, López de Azcona y Torre Enciso (1964), y de Parga, Matte y Capdevila (1964), y en los años 60 y 70 realizaron estudios von Raumer (1962, 1963), Ferragne, que realizó una Tesis en la provincia de Orense (1972), Anthonioz en el norte de Portugal (1964, 1966, 1968, 1969), y den Tex (1966). Pero quien dio mayor impulso al conocimiento de la geología de Galicia fue la escuela de Leiden, dirigida por Den Tex, a la que Parga Pondal, cuyos estudios sobre Galicia fueron también importantes, dio una buena acogida a través de su Laboratorio de Lage, y cuyo tema de trabajo era esencialmente la petrología, que no se está considerando aquí, más que de un modo muy somero.

Sobre lo que aquí se quiere llamar la atención es sobre los macizos con rocas básicas y ultrabásicas que se encuentran en varias localidades de Galicia y el norte de Portugal, y que, como consecuencia de las deformaciones más tardías, ocupan áreas sinformes. Las áreas con rocas básicas y ultrabásicas, que pueden tener forma alargada o más frecuentemente en cubeta, alguna de las cuales, como las de Cabo Ortegal, aparecen ya en el mapa de Schulz, fueron primero interpretadas como un lopolito (Parga, 1956, 1963), y después como alóctonos por Ribeiro (Ribeiro et al., 1964; Ribeiro, 1970) y por Anthonioz (1964, 1968), si bien estos mismos autores en algunos trabajos (Anthonioz, 1966) muestran dudas sobre su significado o presentan las dos hipótesis, aunque inclinándose por la última (Ribeiro et al., 1966). Más tarde, la escuela de den Tex tomó una posición a favor de la autoctonía (den Tex, Kuijper y Arps, 1983a, 1983b; den Tex, 1975; Engels y Vogel, 1972; Keasberry, Calsteren y Kuijper, 1976) y los consideró el resultado de la evolución de una "mantle plume" (Calsteren, 1977a, 1978a, 1978b; van Calsteren et al., 1979; denTex 1981a, 1981b). Como consecuencia, el mismo Ribeiro aceptó este modelo y los interpretó como enraizados, con forma más o menos de hongo (Matte y Ribeiro, 1967), interpretación que Matte siguió manteniendo en su Tesis (1968). Finalmente, con motivo de una reunión internacional sobre el NW Peninsular, Ries y Shakleton (1971), que asistieron a la misma, hicieron una publicación con una interpretación completamente aloctonista (fig. 26). Esta publicación fue el detonante que avivó el debate sobre estos macizos (Overmeeren, 1975; Bayer y Matte, 1979) y que condujo a que la aloctonía de los complejos con rocas básicas y ultrabásicas fuera pronto aceptada (Ribeiro, 1983; Iglesias, M. L. Ribeiro, A. Ribeiro, 1983; Ortega Gironés y Gil Ibarguchi, 1983).

\section{La interpretación de la faja orogénica del NW peninsular}

Los datos reunidos sobre la geología del NW de España permitieron la publicación en 1967 de un mapa geológico del Noroeste Peninsular, que se preparó bajo la dirección de Parga Pondal. A principios de los 70, el conjunto de las tres zonas, Cantábrica, Asturoccidental-leonesa y Galicia (la parte adyacente de la Zona Centroibérica), se perfila claramente como una rama de la cordillera hercínica en la que de oeste a este se pasa desde una zona profunda en Galicia, con abundantes granitoides y un metamorfismo de alto grado, y con una lámina cabalgante de rocas básicas y ultrabásicas (Ries y Shackleton, 1971), a una zona de pliegues tumbados, con foliaciones tectónicas (Matte, 1968; Zona Asturoccidental-leonesa) y un metamorfismo decreciente de oeste a este (Capdevila, 1969), hasta una zona frontal con la cobertera despegada de su 


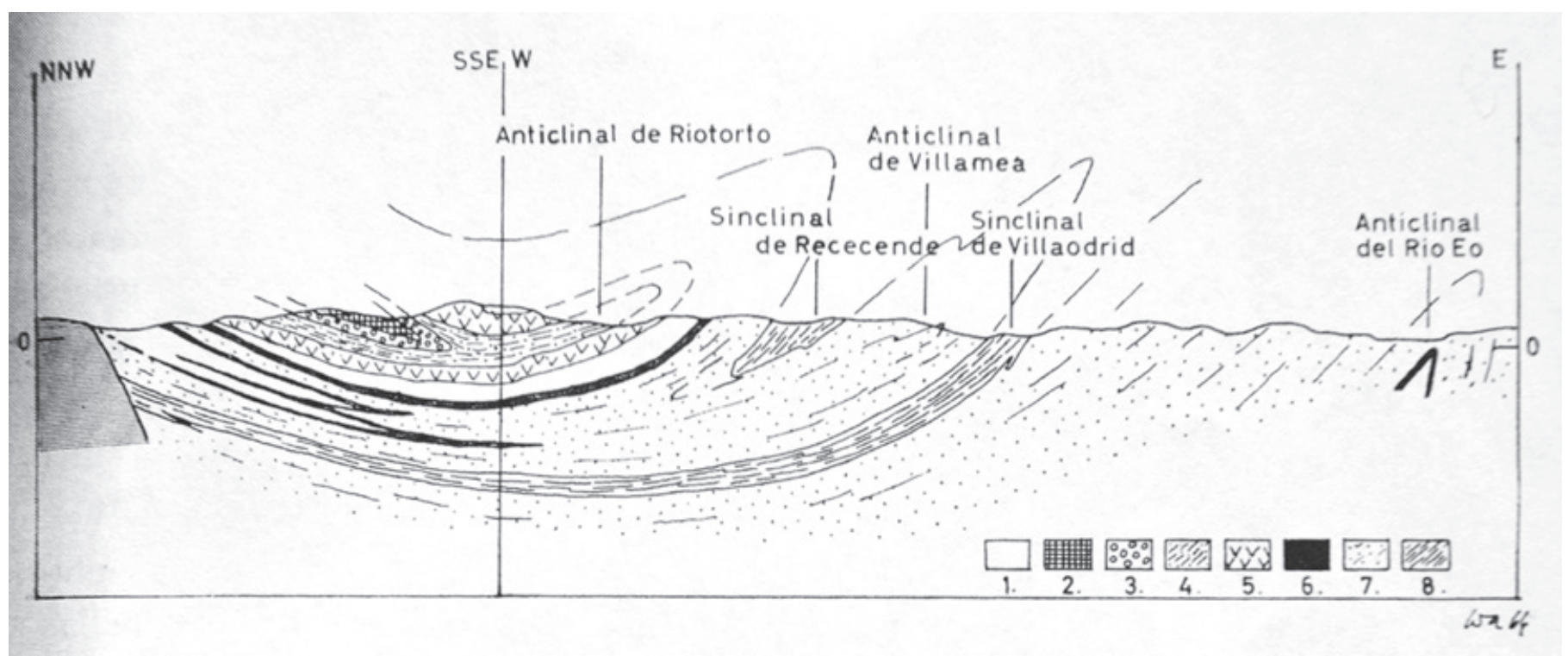

Figura 22. Corte geológico del Manto de Mondoñedo, según Walter (1966). 1: Granito de dos micas; 2: Infrcámbico; 3: Cuarcita de Cándana inferior; 4: Pizarras de Cándana. 5: Cuarcita de Cándana superior, 6: Caliza de Vegadeo; 7: Cámbrico medio y superior: 8: Ordovícico y Silúrico.

Figure 22. Geological cross-section of the Mondoñedo nappe, according to Walter (1966). 1: Two-mica granite; 2:Pre-Cambrian; 3: Lower Cándana quartzite; 4: Cándana shales; 5: Upper Cándana quartzite; 6: Vegadeo limestone; 7: Middle and Upper Cambrian; 8: Ordovician and Silurian.

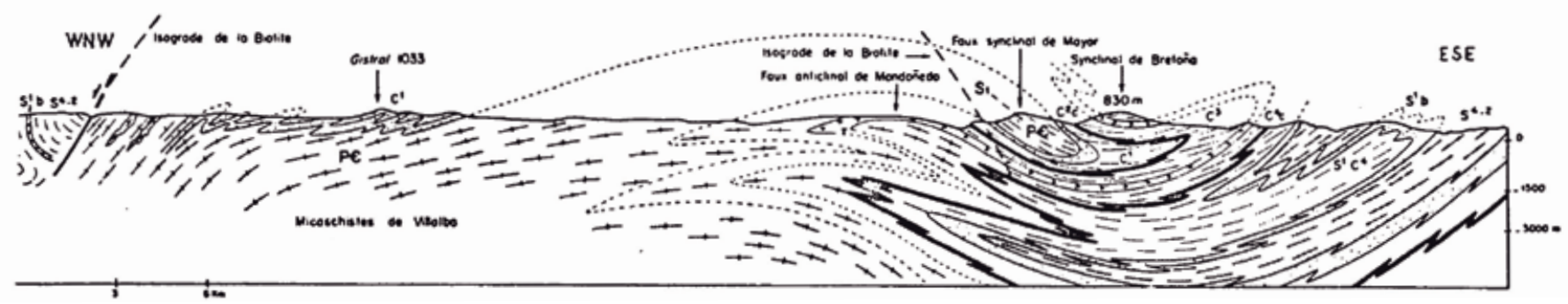

Figura 23. Corte del Manto de Mondoñedo (Matte 1968).

Figure 23. Cross-section of the Mondoñedo nappe (Matte, 1968).

sustrato, formando un conjunto de escamas y mantos ("foreland fold and thrust belt") (Julivert, 1971; Zona Cantábrica).

Si se unen en un "collage" los cortes publicados de las tres zonas en los trabajos antes citados, aparece ya la estructura de la cadena. En el corte resultante de este "collage", aunque esquemáticamente, las características de la Cordillera quedan ya establecidas en sus líneas generales y puede ya presentarse un mapa tectónico del NW peninsular (fig. 27). Con posteriori- dad a la publicación de los segmentos con los que se puede formar este "collage" han aparecido estudios más precisos sobre algunas áreas y se han publicado diversos cortes ya sea de conjunto o de determinados sectores, aunque falta todavía un corte total riguroso, apoyado en datos sísmicos y teniendo en cuenta los espesores y los buzamientos reales, transformados estos últimos a su valor aparente a lo largo de la línea del corte, pero nada de ello modifica el esquema de conjunto. 

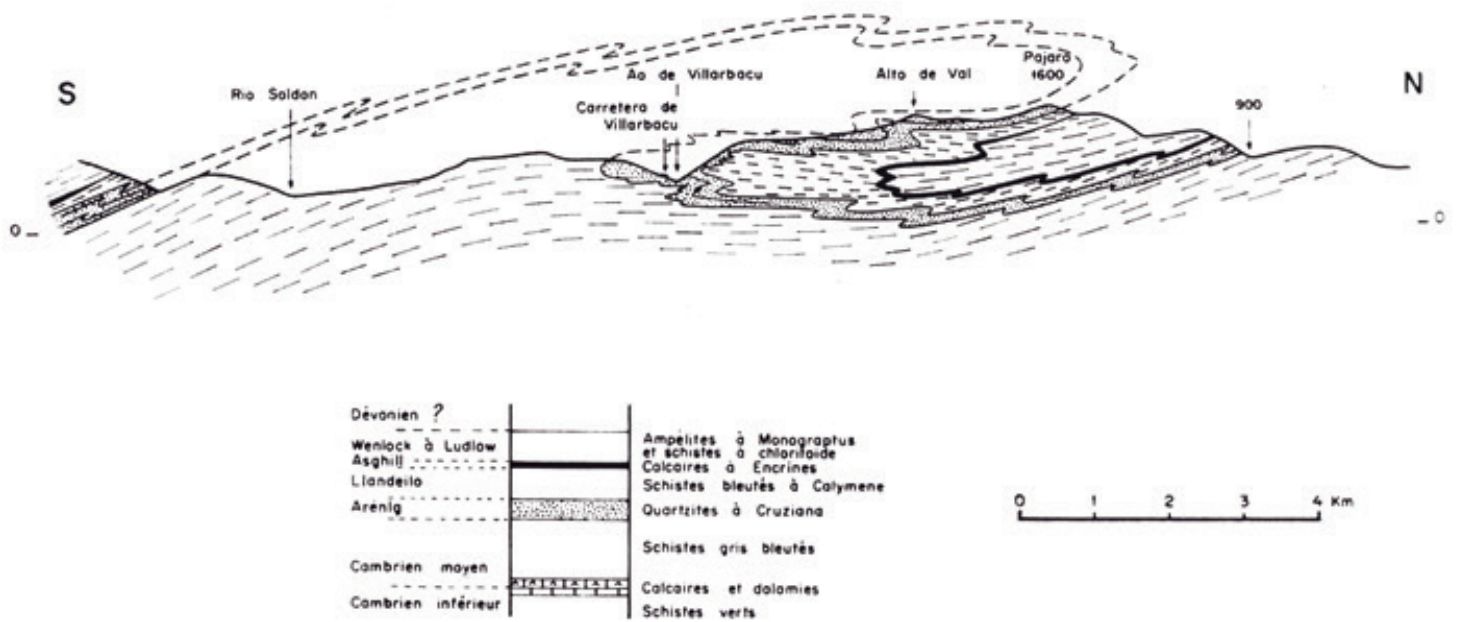

Figura 24. Corte del Manto del Caurel (Matte, 1968).

Figure 24. Cross-section of the Caurel nappe (Matte, 1968).

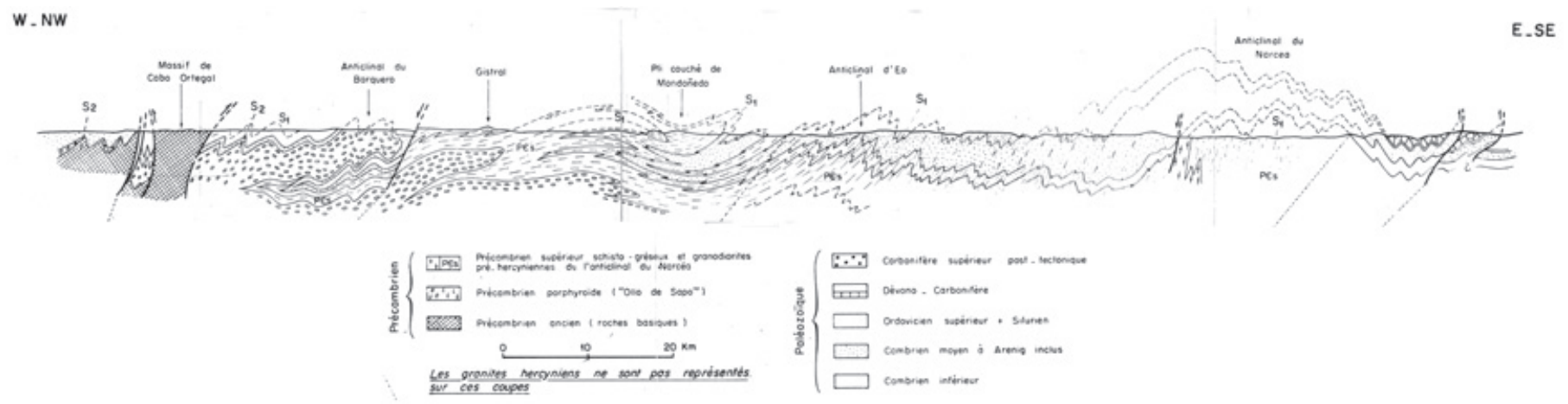

Figura 25. Corte estructural a través de la Zona Asturoccidental-leonesa (Matte, 1968).

Figure 25. Structural cross-section of the Western Asturian-Leonese Zone (Matte, 1968).

\section{Rumbos diversos}

Termino este análisis del progreso del conocimiento de la estructura de la parte norte del orógeno hercínico ibérico, en el momento en que la estructura general de la rama norte del Macizo lbérico queda establecida, es decir al comienzo de los años 70, sin que con esto quiera indicar que la geología no haya seguido progresando. Desde aquellas fechas han pasado ya bastantes décadas y los estudios geológicos en el noroeste de la península han seguido avanzando. Aparte de aportarse más precisiones en la cartografía o en el modelo de cordillera ya expuesto, las investigaciones han ido tomando nuevos rumbos que van a citarse aquí solo muy someramente. Pérez Estaún (2005), en su análisis sobre el papel del Plan MAGNA, da también una serie de datos sobre los nuevos rumbos tomados por la geología española. Aquí van a darse tan sólo unas pinceladas muy someras sobre las diferentes líneas de trabajo o sobre los debates que se han abierto sobre algunos puntos a partir de 1980. Se han realizado nuevos trabajos sobre el Manto de Mondoñedo (Bastida y Pulgar, 1978; Martínez-Catalán, 1980, 1981; Bastida et al., 1986; Aller y Bastida, 1993; Martínez-Catalán et al., 2003; Marcos, 2014). Se han hecho estudios estructurales sobre diferentes temas, como la deformación de series discordantes, la clasificación de pliegues, aspectos geométricos diversos, sistemas de fallas de "strike-slip", etc. (Reading, 1980; Alonso, 1985, 1987, 1989; Pluum et al., 1986; Farias y Heredia, 1994; Alonso et al., 2006, 2009), análisis del plegamiento en el NW de la Península (Fernández et 

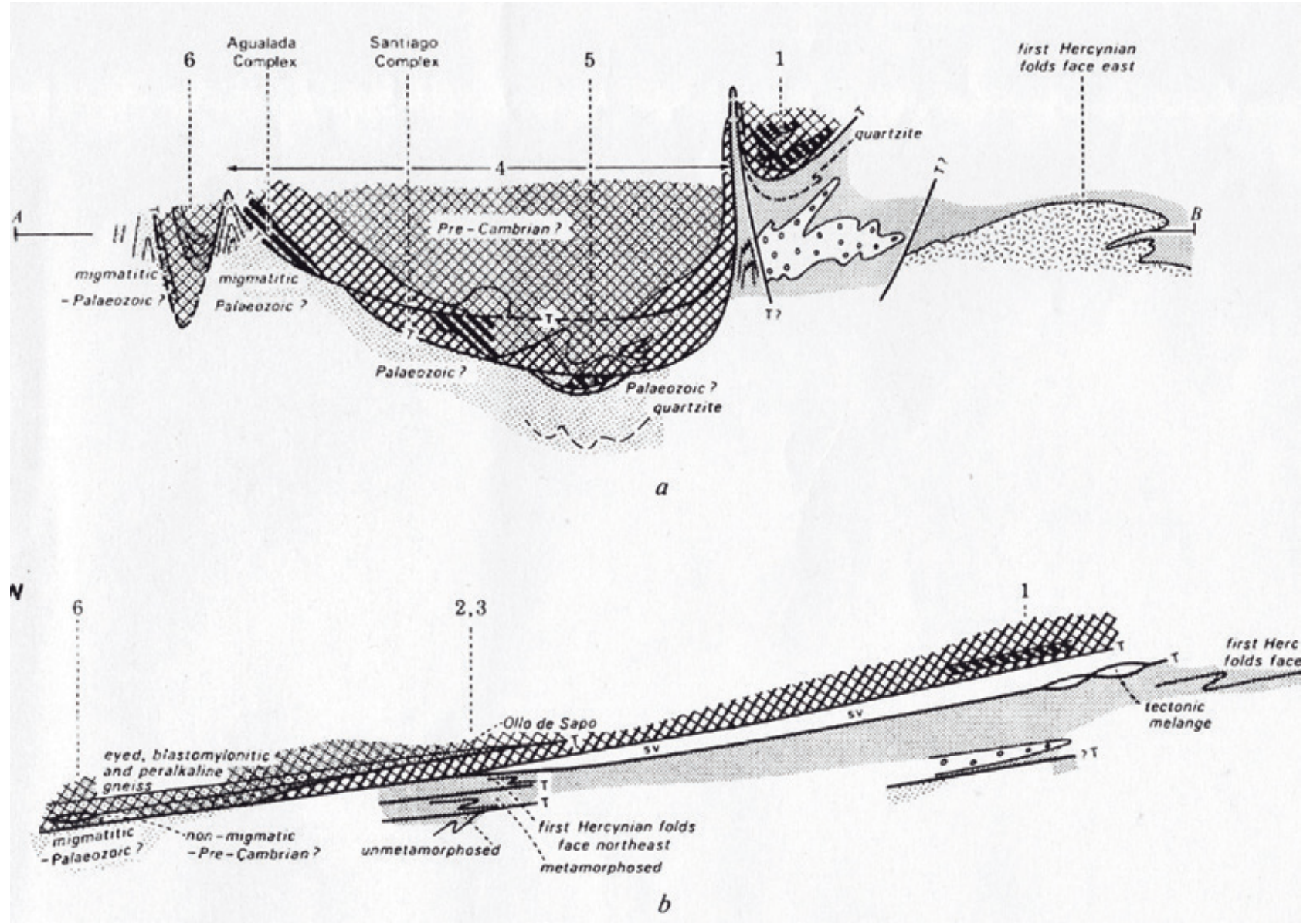

Figura 26. Interpretación aloctonista de los macizos básicos-ultrabásicos de Galicia, según Ries y Shackleton (1971). Arriba: Corte geológico mostrando la estructura actual. Abajo: Disposición de la lámina cabalgante, antes de su plegamiento y de alcanzar su disposición actual. Figure 26. Alloctonist interpretation of the basic-ultrabasic massifs of Galicia, according to Ries and Shackleton (1971). Above: geological cross-section showing the current structure. Below: situation of the thrust sheet before folding and reaching its current location.

al., 2007; Bastida et al., 2010). Se han iniciado estudios geofísicos, como el de las anomalías magnéticas en la Zona Cantábrica (Aller, 1994) y en Galicia oriental (Aller et al., 1994), y el trazado de perfiles sísmicos. En esta línea, para complementar el amplio conocimiento existente sobre la geología de superficie, se llevó a cabo un gran proyecto de sísmica de reflexión profunda (Proyecto ESCI-N), en el cual se realizaron en el NW peninsular, entre 1991 y 1993, cuatro perfiles, que aportaron una gran información sobre la geología del subsuelo. Sus resultados dieron lugar a un volumen monográfico de la Revista de la Sociedad Geológica de España (Santanach, Ed., 1995), así como a otras muchas publicaciones (una síntesis de los resultados puede verse en Fernández Viejo y Gallastegui, 2005). Se han estudiado las foliaciones incipientes, en relación con muy bajos grados de metamorfismo y con la cristalinidad de las micas (Aller y Brime, 1985; Aller,
1986; Aller et al., 1987; Gutiérrez Alonso y Nieto, 1996). Se han llevado a cabo estudios paleomagnéticos (Ries et al., 1980; Hirt et al., 1992) y se ha debatido el modo como se ha originado el arco, con dos interpretaciones, el cierre del arco a partir de una estructura rectilínea (Parés at al., 1994) o el cierre progresivo de una estructura curvada, con la terminación lateral de los cabalgamientos cantábricos compensándose en un sistema de pliegues (Julivert y Arboleya, 1984, 1986; Hirt et al., 1992). Sobre el cierre del arco son de citar también, entre otros, los trabajos de Pérez Estaún et al. (1988), Stewart (1995), van der Voo et al., (1997) y Weil et al. $(2000,2001)$. Se han estudiado marcadores de la deformación (Ries y Shackleton, 1976; Hirt et al., 2000). Se han hecho publicaciones sobre las cuencas carboníferas frontales del orógeno y su desarrollo durante la orogénesis (Julivert, 1978; Marcos y Pulgar, 1982) y se han hecho diversos estudios sobre 


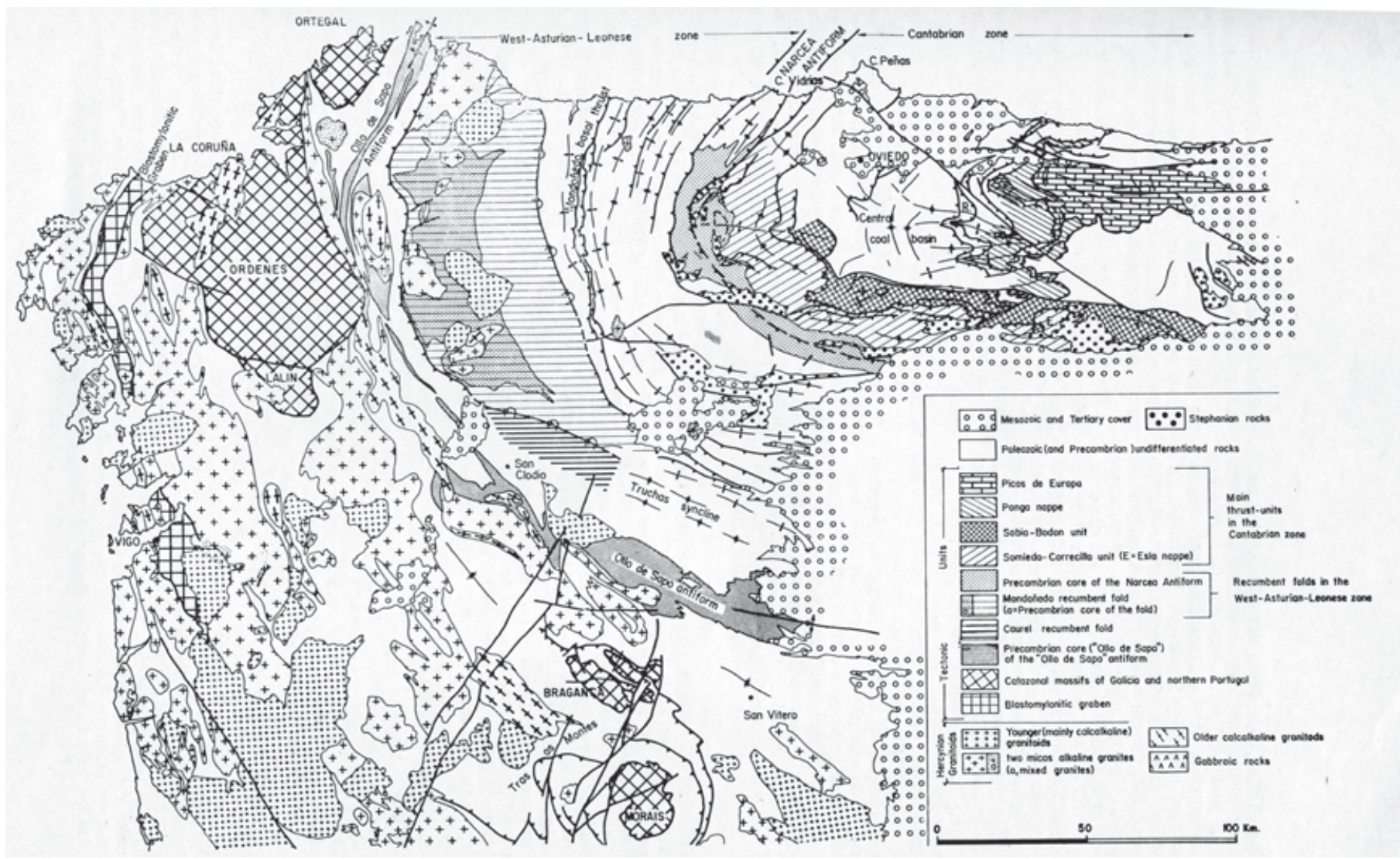

Figura 27. Mapa del NW peninsular, según Julivert, Martínez y Ribeiro (1980), con las distintas unidades estructurales.

Figure 27. Map of the NW of the peninsula, according to Julivert, Martínez and Ribeiro (1980), with the different structural units.

el Carbonífero, que incluyen aspectos de su sedimentación (Maas y van Gilkel, 1983; Navarro et al., 1986). Se han estudiado las zonas deformadas en la base de algunos mantos (Arboleya, 1981, 1989). Se han llevado a cabo estudios de la transición diagénesis/ metamorfismo mediante el índice de alteración del color (CAI) de los conodontos y el índice de Kübler (KI), relacionado con la cristalinidad de la illita, que han permitido realizar mapas de isogradas y establecer la evolución tectonotérmica de la Zona Cantábrica (Raven y van der Pluijm, 1986; García López et al., 1999, 2007, 2013; Bastida et al., 2002). Se han hecho estudios petrológicos con nuevos rumbos y se ha seguido trabajando intensamente sobre los complejos alóctonos de Galicia (Marcos et al., 1984, 2000, 2002; Díaz García, 1990; Ábalos et al., 1994, 2000, 2003; Martínez-Catalán et al., 1996, 2002; Fernández, 1997; Azcárraga, 2000; Azcárraga et al. 2002; Llana Fúnez y Marcos, 2002; Alcock et al., 2005; Puelles et al., 2005; entre muchos otros). Cabe citar, finalmente, la aparición de diversos volúmenes que han aportado una visión sintética y una puesta a punto de los conoci- mientos existentes sobre la geología del orógeno hercínico ibérico en el momento de su publicación (Comba, J. A. Coord., 1983; Dallmeyer y Martínez García Eds., 1990; Gibbons y Moreno Eds., 2002; Vera Ed., 2004, entre otros).

Termino este apunte sobre los nuevos rumbos tomados por la geología en 2014, fecha del último trabajo que cito en este apartado. Las ligeras pinceladas dadas en él hacen referencia a temas aún demasiado vivientes, y creo que debe esperarse la perspectiva de los años antes de intentar un estudio histórico.

\section{Agradecimientos}

Agradezco a Fernando Bastida, Susana García-Lópezy Francisco González Lodeiro las sugerencias realizadas al manuscrito original, a los revisores Ricardo Arenas y José Ramón Martínez Catalán sus acertados comentarios que colaboraron a mejorar el texto y las ilustraciones, y a Isabel Rábano la labor editorial. 


\section{Referencias}

Ábalos, B., Mendía, M. y Gil Ibarguchi, J. I., 1994. Structure of the Cabo Ortegal eclogite-facies zone (NW Iberia). Comptes Rendus de l'Académie des sciences Paris, 319, 1231-1238.

Ábalos, B., Puelles, P. y Gil Ibarguchi, J. I. 2003. Structural assemblage of high-pressure mantle and crustal rocks in a subduction channel (cabo Ortegal, NW Spain). Tectonics, 22, 1-21.

Ábalos, B., Azcárraga, J., Gil Ibarguchi, J. I., Mendía, M. y Puelles, P. 2000. Mapa Geológico del Complejo de Cabo Ortegal (NO de España). Instituto Universitario de Xeoloxía Isidro Parga Pondal, Universidad de La Coruña, 60 pp.

Adaro, L. de, 1914. Emplazamiento de sondeos para investigar la probable prolongación de los senos hulleros por bajo de los terrenos mesozoicos. Boletín del Instituto Geológico de España (2 $2^{\text {a }}$ ser.), 14, 9-79.

Adaro, L. de, 1926. Atlas del estudio estratigráfico de la Cuenca Hullera Asturiana. Instituto Geológico de España, Madrid, 10 láms.

Adaro, L. de y Junquera, G. 1916. Hierros de Asturias. In: Criaderos de Hierros de España. Instituto Geológico de España, Madrid, 610 pp.

Aller, J. A., 1986. La estructura del sector meridional de las unidades del Aramo y Cuenca Carbonífera Central. Consejería de Industria y Comercio (Principado de Asturias), $180 \mathrm{p}$.

Alcock, J. E., Arenas, R. y Martínez-Catalán, J. R. 2005. Shear stress in subducting continental margin from high-pressure, moderate-temperature metamorphism in the Ordenes Complex, Galicia, NW Spain. Tectonophysics, 397, 181-194.

Aller, J. A., Bastida, F., Brime. C. H. y Pérez Estaún, A. 1987. Cleavage and its relation with metamorphic grade in the Cantabrian Zone (Hercynian of the North-West Spain). Sci. Géol., Bull., 40 (3), 255-272.

Aller, J. A. 1994. A21/2D interpretation of the Cantabrian Zone magnetic anomaly using geological and geophysical constraints: structural implications. Revista de la Sociedad Geológica de España, 7 (3-4), 327-334.

Aller, J. y Bastida, F. 1993. Anatomy of the Modoñedo Nappe basal shear zone (NW Spain). Journal of Structural Geology, 15, 1405-1419.

Aller, J. A. y Brime, C. 1985. Deformación y metamorfismo en la parte sur de la Cuenca arbonífera Central (NO de España). Compte Rendu X Congr. Inrt. Strat. Géol. Carbon., Madrid, 3, 541-548

Aller, J., Zeyen, H. J., Pérez Estaún, A., Pulgar, J. A. y Parés, J. M. 1994. A 2.5D interpretation of the eastern Galicia magnetic anomaly: geodynamical implications. Tectonophysics, 237, 201-213.

Almela, A. y Ríos, J. M. 1955. Datos para el conocimiento de la Geología asturiana (Valles de Riosa y Proaza). Bo- letín del Instituto Geológico y Minero de España, 45, 54 pp.

Almela, A. y Ríos, J. M. 1962. Investigación del Hullero bajo los terrenos mesozoicos de la Costa Cantábrica (Zona de Oviedo-Gijón-Villaviciosa-Infiesto). Empresa Nacional "Adaro" de Investigaciones Mineras, Madrid, $171 \mathrm{pp}$.

Alonso, J. L. 1985. Estructura y evolución tectonoestratigráfica de la región del Manto del Esla (Zona Cantábrica, NW de España). Diputación Provincial de León, León, 276 pp.

Alonso, J. L. 1987. Estructura y evolución tectónica de la región del manto del Esla. Instituto "Fray Bernardino de Sahagún", León, 276 p.

Alonso, J. L. 1989. Fold reactivation involvimg unconformable sequences: theoretical análisis and natural examples from the Cantabrian Zone (Northwest Spain). Tectonopysics, 170, 17-77.

Alonso, J. L., Marcos, A. y Suárez, A. 2006. Structure and organization of the Porma Mélange: progressive denudation of a submarine nappe toe by gravitational collapse. American Journal of Science, 306, 32-65.

Alonso, J. L., Marcos, A. y Suárez A. 2009. Paleogeographic inversion resulting from large out of sequence breaching thrusts: The León Fault (Cantabrian Zone, NW Iberia). A new picture of the external VariscanThrust Belt in the lbero-Armorican Arc. Geologica Acta, 7, 451-473.

Anónimo, sin fecha (probablemente de los años 40). Cuenca Carbonífera Central de Asturias, E. 1: 80.000. Distrito Minero de Oviedo.

Anthonioz, P. M. 1964. Sur quelques caractères pétrographiques et structuraux de l'unité de Morais. Boletim da Sociedade Geológica de Portugal, 15, 149-156.

Anthonioz, P. M. 1966. Géologie sommaire de la région de Morais (Tras-os-Montes, Portugal). Leidse Geologische Mededelingen, 36, 301-304.

Anthonioz, P. M. 1968. Note preliminaire sur la géologie de I'unité de Bragança, ses rélations avec l'unité de Morais et le contexte regional. Boletim da Sociedade Geológica de Portugal, 16 (3), 221-226.

Aramburu, C. y Bastida, I. (Eds.) 1995. Geología de Asturias. Ediciones Trea, Gijón, 314 pp.

Arboleya, M. L. 1981. La estructura del manto del Esla (Cordillera Cantábrica). Boletín Geológico y Minero, 92 (1), $19-40$.

Arboleya, M. L. 1989. Fault rocks of the Esla Thrust (Cantabrian Mountains, N Spain), an example of foliated cataclasites. Annales Tectonicae, 3 (2), 99-109.

Azcárraga, J. 2000. Evolución tectónica y metamórfica de los mantos inferiores de grado alto y alta presión del Complejo de Cabo Ortegal. Instituto Universitario de Geologia, Universidad de La Coruña, Serie NovaTerra, 17, 306 pp.

Azcárraga, J., Ábalos, B. y Gil Ibarguchi, J. I. 2002. On the relationship between kilometer-scale sheath folds, ductile thrusts and minor structures in the basal high-pressure units of the Cabo Ortegal complex (NW Spain). Journal of Structural Geology, 24, 1971-1989. 
Barrois, Ch.1882. Recherches su les terrains anciens des Asturias et de la Galice. Mémoires de la Société géologique du Nord, 2 (1), 1-630.

Bastida, F. y Pulgar, J. 1978. La estructura del Manto de Mondoñedo entre Burela y Tapia de Casariego (Costa Cantábrica, España). Trabajos de Geología, 10, 75-124.

Bastida, F., Martínez-Catalán, J. R. y Pulgar, J.A. 1986. Structural, metamorphic and magmatic history of the Mondoñedo nappe (Hercynian belt, NW Spain). Journal of Structural Geology, 8, 415-430.

Bastida, F., Aller, J., Pulgar, J. A., Toimil, N. C., Fernández, F.J., Bobillo-Ares, N. C. y Menéndez, C. O. 2010. Folding in orogens: a case study in de northern Iberian Variscan Belt. Geological Journal, 45, 597-622.

Bastida, F., Brime, C., García-López, S., Aller, J., Valín, M. L. y Sanz-López, J. 2002. Tectono-thermal evolution of the Cantabrian Zone (NW Spain). In: S. García-López y F. Bastida (Eds.), Palaeozoic Conodonts from Northern Spain. Cuadernos del Museo Geominero, 1. Instituto Geológico y Minero de España, Madrid, 105-123.

Bayer, R. y Matte, P. 1979. Is the mafic/ultramafic massif of Cabo Ortegal (NW Spain) a nappe emplaced during a variscan obduction? A new gravity interpretation. Tectonophysics, 57, 9-18.

Bertrand, L. y Mengaud, L. 1912a. Sur la structure des Pyrénées Cantabriques entre Santander et Llanes et leurs rélations probables avec les Pyrénées. Bulletin de la Société Géologique de France, 12, 504-545.

Bertrand, L. y Mengaud, L. 1912b. Sur la structure de plusieures nappes superpostes dans la Cordillère Cantabrique entre Santander et Llanes. Comptes Rendus de I'Académie des sciences Paris, 155, 737-740.

Bertrand, L. y Mengaud, L. 1912c. Sur la structure des Pyrénées Cantabriques entre Santander et Llanes et leurs relations probables avec les Pyrénées occidentales. Comptes Rendus de l'Académie des sciences Paris, 155, 984-987.

Bosch, W. J. van den, 1969. Geology of the Luna-Sil region, Cantabrian Mountains (NW Spain). Leidse Geologische Mededelingen, 44, 137-225.

Boschma, D. 1968. Provisional geologic map of the southern Cantabrian Mountais. Leidse Geologische Mededelingen, 43, 217-220.

Botella, F. de, 1879. Mapa Geológico de España y Portugal, E 1:2.000.000. Madrid.

Brower, A. 1968. Devonian of the Cantabrian Mountains, Northwestern Spain. International Symposium on the Devonian System, Calgary 1967, 2, 37-45.

Calderón, S. 1885. Ensayo orogénico sobre la Meseta Central de España. Anales de la Sociedad Española de Historia Naturl, 14, 131-172.

Calsteren, P. W. C. van, 1977. A mantel-plume-model interpretation for the Paleozoic geology of Galicia with emphasis in the Cabo Ortegal area. Proc. Konink. Ned. Ak. Van Wetensch., serie B, 80 (3), 156-168.
Calsteren, P. W. C. van, 1978a. Geochronological, geochemical and geophysical investigations in the high-grade mafic-ultramafic complex at Cabo Ortegal and other pre-existing elements in the Hercynian basement of $\mathrm{Ga}$ licia (NW Spain). Leidse Geologische Mededelingen, 51 (1), 57-61

Calsteren, P. W. C. van, 1978b. Geochemistry of the polymetamorphic maphic-ultramaphic complex of Cabo Ortegal (NW Spain). Lithos, 11, 61-72.

Calsteren, P. W. C. van y Tex, E. Den, 1978. An early paleozoic continental Rift system in Galicia (NW Spain). In: I. B. Ramberg y E. R. Neuman (Eds.), Tectonic and Geophysics of Continental Rifts. Springer, Dordrecht, 125-132.

Calsteren, P. W. C. van, Boelrijk N. A. I. M., Hebeda, E. H., Priem H. N. A., Tex, E. Den, Verdurmen, E. A. Th. y Verschure, R. H. 1979. Isotopic dating of older elements (including the Cabo Ortegal mafic-ultramafic complex) in the Hercynian orogen of NW Spain: manifestations of a presumed Early Paleozoic mantle plume. Chemical Geology, 24, 35-36.

Capdevila, R 1967. Extension du métamorphisme régional hercynien dans le nordouest de I'Espagne (Galice oriental, Asturias, León). C. R. Somm. Soc. Geol. Fr., 7, 277-279.

Capdevila, R. 1969. Le metamorphisme régional progressif et les granites dans le segment hercynien de Galice nord orientale (NW de l'Espagne). Thèse Montpelier, $430 \mathrm{p}$.

Capdevila, R., 1976. Mise en evidence d'une zonation géochimique dans les granodiorites hercyniennes du NW de la Péninsule Ibérique: consequences sur l'interpretation de la Chaîne Hercynienne dans cette région. 4èmme Reun. Intern. Sc. de la Terre: 94.

Capdevila, R. y Floor, F. 1970. Les differents types de granites hercyniens et leur distributian dans le nord-ouest de I'Espagne. Boletín Geológico y Minero, 81 (2-3), 216-225.

Carey, S. W. 1958.-The tectonic approach to continental drift. In: Contiental Drift, A Symposium: 177-355.

Carlé, W. 1945a. Jung-silurische Untersuchungen im Grundgebirge von Galicien (Norspanien). Geotektonische Forschungen, 6, 13-36.

Carlé, W. 1945b. Ergebnisse geologische Untersuchungen im Grundgebirge von Galicien (Nordwest Spanien). Geotektonische Forschungen, 6 (traducido en Publicaciones Extranjeras sobre Geología de España, CSIC, 5: 61-90).

Comba, J. A. (Coord.) 1983. Libro jubilar J. M. Ríos: Geología de España. Instituto Geológico y Minero de España, Madrid, 656 pp.

Compte, P. 1959. Recherches sur les terrains anciens de la Cordillère Cantabrique. Memorias del Instituto Geológico y Minero de España, 60, 440 pp.

Cortázar, D. 1890. Descripción geológica de la provincia de Segovia. Boletín de la Comisión del Mapa Geológico de España, 17, 234 pp.

Cortázar, D. 1907. Mapa Geológico de España 1:400.000, segunda edición. Comisión del Mapa Geológico de España, Madrid. 
Dallmeyer, R. D. y Martínez García, E. (Eds.) 1990. Pre-Mesozoic geology of Iberia. Springer-Verlag, Berlín, 416 pp.

Delesse, M. 1875. Sur le granite et sur les roches métamorphiques. Bulletin de la Société Géologique de France (3e sér.), 3, 154-160.

Díaz García, F. 1990. La geología del sector occidental del complejo de Órdenes (Cordillera Hercínica, NW de España). Instituto Universitario de Geología, Universidad de La Coruña, Serie NovaTerra, 3, 230 pp.

Egozcue, J. y Mallada, L. 1876. Memoria geológico-minera de la provincia de Cáceres. Memorias de la Comisión del Mapa Geológico de España, 4, 368 pp.

Evers, H. J. 1967. Geology of the Leonides between the Bernesga and Ponga rivers, Cantabrian Mountains. NW Spain. Leidse Geologische Mededelingen, 41, 83-151

Ezquerra del Bayo, J. 1850. On the Geology of Spain. Journal Geological Society London, 6, 406-413.

Ezquerra del Bayo, J. 1850-57.- Ensayo de una descripción general de la estructura geológica de los terrenos de España en la Península. Memorias de la Real Academia de Ciencias, Madrid ( $3^{\mathrm{a}}$ ser. Ciencias Nat.). 1 (1), 1850, 35-65; 1 (2), 1851, 74-107, 1 (3) 1854, 161-184; 4(1), 1856, 115$155 ; 4(2)$ 1857, 351-359.

Färber, A. y Jaritz, W. 1964. Die Geologie des Westasturischen Küstengebietes zwischen San Esteban de Pravia und Ribadeo. Geologisches Jahrbuch, 81, 679-738.

Farias, P. 1982. La estructura del sector central de los Picos de Europa. Trabajos de Geología (Univ. Oviedo), 12, 63-72.

Farias P. y Heredia, N. 1994. Geometría y cinemática de los duplex de Pambuches (Unidad de los Picos de Europa, Zona Cantábrica, NO de España). Revista de la Sociedad Geológica de España, 7, 113-120.

Fernández, F. J., Aller, J. y Bastida, F. 2007. Kinematics of a kilometric recumbent fold: The Caurel syncline (Iberian massif, NW Spain). Journal of Structural Geology, 29, 1650-1664.

Fernández Rodríguez, F. J. 1997. Estructuras desarrolladas en gneises bajo condiciones de alta $P$ y $T$ (Gneises de Chímparra, Cabo Ortegal, A Coruña, Galicia, España). Instituto Universitario de Geología, Universidad de La Coruña, Serie Nova Terra, 13, 250 pp.

Fernández Viejo, G. y Gallastegui, J. 2005.The ESCI-N Project after a decade: a synthesis of the results and open questions. Trabajos de Geología, Univ. de Oviedo, 25, 8-25.

Ferragne, A. 1972. Le Cambrien et le Paléozoique de la province d'Orense (Nord-Ouest de l'Espagne). Thèse Univ. Bordeaux l, 269 p.

Frets, D. C. 1965. The geology of the southern part of the Pisuerga basin and the adjacent area of Santibanez de Resoba, Palencia, Spain. Leidse Geologische Mededelingen, 31, 113-162.

García Fuente, S. 1959. Explicación de la Hoja núm. 77, La Plaza (Teverga). Mapa Geológico de España a escala 1:50.000. Instituto Geológico y Minero de España, Madrid, 68 pp.
García-López, S., Bastida, F., Brime, C., Aller, J., Valín, M. L., Sanz-López, J., Méndez, C.A. y Menéndez, J. R. 1999. Episodios metamórficos en la Zona Cantábrica y su contexto estructural. Trabajos de Geología, Universidad de Oviedo, 21, 177-187.

García López, S., Bastida, F., Aller, J., Sanz-López, J., Marín, J.A. y Blanco-Ferrera, S. 2013. Tectonothermal evolution of a major thrust system: the Esla-Valsurbio unit (Cantabrian Zone, NW Spain). Geological Magazine, 150, 1047-1061.

García López, S., Brime, C., Valín, M. L., Sanz-López, J., Bastida, F., Aller, J. y Blanco-Ferrera, S. 2007. Tectonothermal evolution of a foreland fold and thrust belt: the Cantabrian Zone (Iberian Variscan belt, NW Spain). Terra Nova, 19 (6), 469-475.

García Loygorri, A., Ortuño, G., Caride, C., Gervilla, M., Greber, Ch. y Feys, R., 1971. El Carbonífero de la Cuenca Central de Asturias. Trabajos de Geología, Univ. de Oviedo, 3, 101-150.

Gibbons, W. y Moreno, T. (Eds.) 2002. The Geology of Spain. The Geological Society, London, $649 \mathrm{pp}$.

Gómez de Llarena, J. y Rodríguez Arango, C. 1948. Datos para el estudio geológico de la Babia Baja (León). Boletín del Instituto Geológico y Minero de España, 61, 79-206.

Grand'Eury, C. 1887. Flore du terrain huiller de Mieres. Annales des Mines, $7^{\mathrm{a}}$ ser., 12, 372.

Gutiérrez Alonso, G. y Nieto, F. 1996. White-mica “crystallinity", finite strain and cleavage development across a large variscan structure, NW Spain. Journal Geological Society London, 153, 287-299.

Helmig, H. M. 1965. The geology of the Valderrueda, Tejerina, Ocejo and Sabero coal basins (Cantabrian Mountains, Spain). Leidse Geologische Mededelingen, 32, 75-149.

Hernández Pacheco, E. 1912. Ensayo de síntesis geológica del Norte de la Península Iberica. Trabajos del Museo de Ciencias Naturales, Junta para Ampliación de Estudios e Investigaciones Científicas, Madrid, 133 pp.

Hernández Pacheco, E. 1913. Datos respecto a la orogenia de Asturias. Boletín de la Sociedad Española de Historia Natural, 13, 143-147.

Hernández Sampelayo, P. 1922. Criaderos de hierro de España. Tomo IV: Hierros de Galicia. Memorias del Instituto Geológico y Minero de España, 438 pp.

Hernández Sampelayo, P. 1928. Sobre la tectónica de España. Notas y Comunicaciones del Instituto Geológico de España, I (1), 31-34.

Hirt, A. M., Julivert, M. y Soldevila, J. 2000. Magnetic fabric and deformation in the Navia-Alto Sil slate belt, northwestern Spain. Tectonophysics, 320, 1-16.

Hirt, A. M., Lowrie, W., Julivert, M. y Arboleya, M. L., 1992. Paleomagnetic results in support for the origin of the Asturian Arc. Tectonophysics, 213, 321-339.

Julivert, M. 1960. Estudio geológico de la Cuenca de Beleño (valles altos del Sella, Ponga, Nalón, y Esla, de la CordiIlera Cantabrica). Boletín del Instituto Geológico y Minero de España, 71, 1-364. 
Julivert, M. 1963. Estudio geológico de la Sierra del Aramo, cuenca de Riosa, y extremo meridional de la cuenca de Quirós. Boletín del Instituto Geológico y Minero de España, 74, 87-171.

Julivert, M. 1965. Sur la tectonique hercynienne à nappes de la Chaine Catabrique (étude géologique de la région a l'est du Basin Central, Epagne. Bulletin de la Société Géologique de France, $7^{\mathrm{a}}$ ser., 7 (4), 644-651.

Julivert, M. 1967a. La ventana tectónica del Río Color y la prolongación septentrional del manto del Ponga (Cordillera Cantábrica, España). Trabajos de Geología (Univ. Oviedo), 1, 1-26.

Julivert, M. 1967b. La ventana tectónica del Río Monasterio y la prolongación meridional de manto del Ponga (Cordillera Cantábrica, Espña). Trabajos de Geología (Univ. Oviedo), 1, 59-67.

Julivert, M. 1971. Décollement tectonics in the Hercynian Cordillera of northwest Spain. American Journal of Science, 270, 1-29.

Julivert, M. 1976. La estructura de la región de Cabo Peñas. Trabajos de Geología (Univ. Oviedo), 8, 203-309.

Julivert, M. 1978. Hercynian orogeny and Carboniferous paleogeography in northeastern Spain: a model of deformation-sedimentation relationships. Zeitschrift der Deutschen Geologischen Gesellschaft, 129, 1-31.

Julivert, M. 1983. Generalidades. En: Libro Jubilar J. M. Ríos. Geología de España, 1. Instituto Geológico y Minero de España, Madrid, 59-71.

Julivert, M. 2014. Una historia de la geología en España, en su contexto socioeconómico, cultural y político y en el marco de la geología internacional. Publ. i Edic. Univ. Barcelona, $295 \mathrm{pp}$.

Julivert, M. y Arboleya, M. L. 1984. A geometrical and kinematic approach to nappe structure in an arcuate fold belt: the Cantabrian nappes (Hercynian Caín, NW Spain). Journal of Structural Geology, 6 (5), 499-519.

Julivert, M. y Arboleya, M. L. 1986. Areal balancing and estimate of areal reduction in a thin-skinned fold-and-thrust belt (Cantabrian Zone, NW Spain): constraints on its emplacement mechanism. Journal of Structural Geology, 8 (3-4), 407-414.

Julivert, M., Fontboté, J.M., Ribeiro, A. y Conde, L.N 1972. Mapa tectónico de la Península Ibérica y Baleares, Esc. 1:1.000.000. Instituto Geológico y Minero de España, Madrid, $113 \mathrm{pp}$.

Julivert, M. y Marcos, A. 1970. Mapa geológico de España 1:200.000, hoja núm. 9 (Cangas del Narcea). Instituto Geológico y Minero de España, Madrid.

Julivert, M. y Marcos, A. 1973. Superimposed folding under flexural conditions in the Cantabrian Zone (Hercynian Cordillera, North-west Spain). American Journal of Science, 273, 353-375.

Julivert, M., Marcos. A. y Truyols, J, 1972. L'évolution paléogéographique du nord-ouest de I'Espagne pendant I'Or-
dovicien-Silurien. Bulletin de la Société géologique et minéralogique de Bretagne, 4 (1), 1-7

Julivert, M., Marcos, A., Philippot, A. y Henry, J. L. 1968. Nota sobre la extensión de la pizarras ordovícias al E de la cuenca Carbonífera Central de Asturias. Breviora Geologica Asturica, 12 (4), 1-4.

Julivert, M., Pello, J. y Fernández García, L. 1968. La estructura del Manto de Somiedo (Cordillera Cantábrica). Trabajos de Geología (Univ. Oviedo), 2, 1-43

Kanis, J. 1956. Geology of the eastern zone of the Sierra del Brezo (Palencia, Spain). Leidse Geologische Mededelingen, 21 (2), 377-445.

Karrenberg, H. 1934. Die postvarischiche Entwicklung des Kantabro-asturischen Gebirges (Nordwestspanien). Gesselsch. Wissench zu Göttingen, Mth.-Phys. KI., 14911593, (trad. por J. Gómez de Llarena en Publicaciones Extranjeras sobre Geología de España, CSIC, 3: 105-224).

Keasberry, E. J., Kalsteren P. W. C. van y Kuijper, R. P. 1976. Early Paleozoic mantle diapirism in Galicia. Tectonophysics, 31, 61-65.

Koopmans, B. N. 1961-1962. The sedimentry and structural history of the Valsurbio Dome, Cantabrian Mountains, Spain. Leidse Geologische Mededelingen, 48, 121-132.

Kossmat, F. 1927. Gliederung des variszischen Grundgebirges. Abhandlungen des Sächsischen Geologischen Landesamts, 1, 1-39.

Kuijper, R. P. y Arps, C. E. S. 1983a. Los complejos de Ordenes, Lalín y Forcarey. En: Libro Jubilar J. M. Ríos. Geología de España, 1. Instituto Geológico y Minero de España, Madrid, 422-430.

Kuijper, R. P. y Arps, C. E. S. 1983b. Un modelo de evolución basado en el desarrollo de una "mantle plume". En: Libro Jubilar J. M. Ríos. Geología de España, 1. Instituto Geológico y Minero de España, Madrid, 435-458.

La Iglesia, A. 1992. Comentarios al artículo cintífico publicado por Louis Proust en 1804 sobre los minerales "platas rojas". Boletín Geológico y Minero, 103 (4), 143-148.

Le Pichon, X., Bonnin, J. y Sibuet, J. 1970. La faille nord-pyrénéenne: faille transformante lièe à l'ouverture du Golfo de Gascogne. Comptes Rendus Geosciences, 271,19411944.

Llana Fúnez, S. y Marcos, A. 2002. Structural record during exhumation and emplacement of high-pressure-low- to intermediate-temperature rocks in the Malpica-Tui unit (Variscan Belt of Iberia). En: Martínez Catalán, J.R., Hatcher, R.D., Jr., Arenas, R., and Díaz García, F., (Eds.), Variscan-Appalachian dynamics: The building of the late Paleozoic basement. Geological Society of America Special Paper 364, 125-142.

Llopis Lladó, N. 1950a. Mapa geológico de los alrededores de Oviedo a escala 1:25.000. Instituto de Estudios Asturianos, Diputación Provincial de Oviedo.

Llopis Lladó, N. 1950b. Mapa geológico de las Sierras de la Coruxera, La Mostayal y Monsacro a escala 1:25.000. 
M. Julivert, 2020. El progreso del conocimiento de la estructura geológica del noroeste... Boletín Geológico y Minero, 131 (4): $661-693$

Instituto de Estudios Asturianos, Diputación Provincial de Oviedo.

Llopis Lladó, N. 1961. Estudio geológico sobre el plutón de Boal (Asturias) y sus yacimientos de wolframio. Breviora Geologica Asturica, 5 (3-4), 3-42.

Llopis Lladó, N. 1964. Sur la paleotectonique des Asturies et ses raports avec la moitié occidentale de la Peninsule Ibérique. Breviora Geologica Asturica, 8 (1-4), 91-140.

Lobato, L. 1977. Geología de los valles altos de los ríos Esla, Yuso, Carrión y Deva. Publicaciones del Instituto Fray Bernardino de Sahagún, Diputación Provincial de León, León, 192 pp.

Lotze, F. 1929. Stratigraphie und Tektonik des keltiberischen Grundgebirges (Spanien). Abhandlungen der Gesellschaft der Wissenschaften in Göttingen, Mathematisch-Physikalische Klasse, 14, 1-320.

Lotze, F. 1945a. Einige Probleme der Iberischen Meseta. Geotektonische Forschungen, 6, 1-12.

Lotze, F. 1954b. Zur Gliederung der Varisziden der Iberischen Meseta. Geotektonische Forschungen, 6, 78-92.

Lotze, F. 1961. Das Kambrium Spaniens. Teil I, Stratigraphie. Akademie der Wissenschaften und der Literatur, Abhandlungen der Mathematisch-Naturwissenschaftlichen Klasse, 6, 1-216.

Lotze, F. 1963. Die variszischen Gebirgszusammenhänge im westlichen Europa. Zeitschrift der Deutschen Geologischen Gesellschaft, 115, 913-925.

Lyell, Ch. 1838. Elements of Geology (trad. J. Ezquerra del Bayo, Elementos de Geología, 1847, Imprenta de D. Antonio Yenes, 652 pp.; edición facsímil, 1999, Sociedad Geológica de España).

Maas, K. 1974.The geology of the Liébana, Cantabrian Mountains, Spain; deposition and deformation in a flysch area. Leidse Geologische Mededelingen, 49, 379465.

Maas, K. y van Ginlkel, A. C. 1983. Variscan olistostrome deposition and synsedimentary nappe emplacement, Valdeon area, Cantabrian mountains, Spain. Leidse Geologische Mededelingen, 52, 341-381.

Macpherson, J. 1878. Sobre la existencia de la fauna primordial en la provincia de Sevilla. Anales de la Sociedad Española de Historia Natural, 7, 280-284.

Macpherson, J. 1879. Breve noticia acerca de la especial estructura de la Península Ibérica. Anales de la Sociedad Española de Historia Natural, 8, 5-26.

Macpherson, J. 1883-1884. Sucesión estratigráfica de los terrenos arcaicos de España. Anales de la Sociedad Española de Historia Natural, 12 (1883), 341-378, 13 (1884), 365-418.

Macpherson, J. 1886. Descripción petrográfica de los materiales arcaicos de Galicia. Anales de la Sociedad Española de Historia Natural, 15, 165-203.

Maestre, A. 1864. Bosquejo general geológico de la Península, formado con los documentos existentes hasta el fin de 1863, E 1:2.000.000. Junta General de Estadística, Madrid. Maestre, A. 1880. Descripción física, geológica y minera de la provincia de Salamanca. Memorias de la Comisión del Mapa Geológico de España, 7, 299 pp.

Mallada, L. 1895. Explicación del Mapa Geológico de España. Tomo 1. Rocas hipogénicas y Sistema Estrato-cristalino. Memorias de la Comisión del Mapa Geológico de España, 558 pp.

Mallada, L. y Buitrago, J. 1878. La fauna primordial a uno y otro lado de la Cordillera Cantábrica. Boletín de la Comisión del Mapa Geológico de España, 5, 177-194.

Marcos, A. 1967. Estudio geológico del reborde NW de los de Picos de Europa (región de Onís-Cabrales, Cordillera Cantábrica). Trabajos de Geología (Univ. de Oviedo), 1, 39-46.

Marcos, A. 1968. La tectónica de la unidad de La Sobia-Bodón. Trabajos de Geología (Univ. Oviedo), 2, 59-87.

Marcos, A. 1970. Sobre la presencia de un flysch del Ordovício superior en el occidente de Asturias. Breviora Geológica Asturica, 14 (2), 13-28.

Marcos, A. 1973. Las series del Paleozoico inferior y la estructura herciniana del occidente de Asturias (NW de España). Trabajos de Geología (Univ. de Oviedo), 6, 1-113.

Marcos, A. 2014. Un nuevo mapa geológico de la parte septentrional del Domo de Lugo (Galicia oriental, NO de España): implicaciones sobre la estratigrafía, estructura y evolución tectónica del Manto de Mondoñedo. Trabajos de Geología (Univ. de Oviedo), 33, 171-200.

Marcos, A. y Pulgar, J. A. 1982. An approach to the tectonostratigraphic evolution of the Cantabrian foreland fold and thrust belt, Hercinian Cordillera of NW Spain. Neues Jahrbuch für Geologie und Paläontologie Abhandlungen, 163, 256-260.

Marcos, A., Farias, P., Galán, G., Fernández-Rodríguez, F.J. y Llana-Fúnez, S. 2002. Tectonic framework of the Cabo Ortegal Complex: A slab of lower crust exhumed in the Variscan orogeny (northwestern Iberian Peninsula). En: J.R. Martínez-Catalán, R.D. Hatcher Jr, R. Arenas y F. Díaz García (Eds.), Variscan-Appalachian dynamics: The building of the later Paleozoic basement. Geological Society of America Special Paper, 364, 143-162.

Marcos, A., Fernández-Rodríguez, F.J. y Llana-Fúnez, S. 2000. Structure of the Cabo Ortegal Nappe. Basement Tectonics, 15. Mid-Conference Field-Trip, 15 pp.

Marcos, A., Marquínez, J., Pérez-Estaún, A., Pulgar, J. A. y Bastida, F. 1984. Nuevas aportaciones al conocimiento de la evolucion tectonometamorfica del complejo de Cabo Ortegal (NW de España). Cuadernos do Laboratorio Xeolóxico de Laxe, 7, 125-131.

Marquínez, J. L. 1978. Estudio geológico del sector SE de los Picos de Europa (Cordillera Cantábrica, NW de España). Tabajos de Geología (Universidad de Oviedo), 10, 295-316.

Martínez Alvárez, J. A. 1962. Estudio geológico del reborde oriental de la Cuenca Carbonífera Central de Asturias. Instituto de Estudios Asturianos, 32 pp.

Martínez Catalán, J. R. 1980. L'apparition du chevauchement basal de la nappe de Mondoñedo dans le dôme de Lugo 
M. Julivert, 2020. El progreso del conocimiento de la estructura geológica del noroeste... Boletín Geológico y Minero, 131 (4): $661-693$

(Galice, Espagne). Comptes Rendus de l'Académie des sciences Paris, sér. D, 290, 179-182.

Martínez Catalán, J. R. 1981. Estratigrafía y estructura del Domo de Lugo (sector oeste de la Zona Asturoccidental-leonesa). Tesis Universidad de Salamanca, 317 pp.

Martínez Catalán, J. R. 2012. The Central Iberian arc, an orocline centered in the Iberian Massif and some implications for the Varisca Belt. International Journal of Earth Sciences, 101, 1299-1314.

Martínez Catalán, J. R., Arenas, R., Díaz García, Rubio Pascual, F. J., Abati, J. y Marquínez, J. 1996. Variscan exhumation of a subducted Paleozoic continental margin:The basal units of the Ordenes Complex, Galicia, NW Spain. Tectonics, 15 (1), 106-121.

Martínez Catalán, J. R., Arenas, R. y Díez Balda, M. A. 2003. Large extensional structures developed during emplacement of a crystalline thrust sheet: the Mondoñedo nappe (NW Spain). Journal of Structural Geology, 25, 1815-1839.

Martínez Catalán, J. R., Díaz García, Arenas, R., Abati, J., Castiñeiras, P., González-Cuadra, P., Gómez Barreiro, J. y Rubio Pascual, F. J. 2002. Thrust and detachment systems in the Órdenes Complex (northwestern Spain): Implications in the Variscan-Appalachian geodynamics. En: J.R. Martínez-Catalán, R.D. Hatcher Jr, R. Arenas y F. Díaz García (Eds.), Variscan-Appalachian dynamics: The building of the later Paleozoic basement. Geological Society of America Special Paper, 364, 163-182.

Martínez García, E. 1978. El Cámbrico de los Picos de Europa (Cordillera Cantábrica, NW de España). Trabajos de Geología. (Univ Oviedo), 10, 341-349.

Martínez García, E. 1981. El Paleozoico de la Zona Cantábrica oriental (noroeste de España). Trabajos de Geología (Univ. Oviedo), 11, 95-127.

Martínez García, E. y Rodríguez Fernández, L. R., 1984. Memoria de la Hoja núm. 56, Carreña-Carbrales. Mapa Geológico de España a escala 1:50.000. Instituto Geológico y Minero de España, Madrid.

Matte, P. 1967a. Le Précambrien supérieur schisto-gréseux de I'ouest des Asturies (Nord-Ouest de l'Espagne) et ses rélations aves les séries précambriennes plus internes de l'arc galicien. Comptes Rendus de l'Académie des sciences Paris, 269, 1769-1772.

Matte, P. 1967b. Ls schistosité primaire dans I'arc hercinien de Galice, variations de son pendage parallèlement et perpendiculairment aux structures et rôle des phases de déformation ulterieures. Colloque sur les Étages Téctoniques (1966). Edit á la Baconnière, Neuchâtel, 243-251.

Matte P. 1968. La structure de la virgation hercynienne de Galice (Espagne). Revue de Géologie Alpine, 44, 155-280.

Matte. P. 1969. Les kink-bands. Example de déformation tardive dans I'hercynien du Nord-Ouest de I'Espagne. Tectonophysics, 7 (4), 309-322.

Matte, P. y Ribeiro, A. 1967. Les rapports tectoniques entre le
Précambrien ancien et le Paléozoique dans le Nord Ouest de la Peninsule Ibérique, grandes nappes ou extrusions? Comptes Rendus de l'Académie des sciences Paris, 284, 2268-2271.

Matte, P. y Ribeiro, A. 1975. Forme et orientation de l'ellipsoide de déformation dans la virgation Hercynienne de Galicia: relation avec le plisement et hypothèses sur la génèse de làrc Ibero-Armoricin. Comptes Rendus de l'Académie des sciences Paris, 280, 2825-2828.

Meer Mohr, C. G. van der, 1983. The Lower Paleozoic of the Leonides and Pisuerga-Carrión province in the Cantabrian zone of the northwest Spain. ITC Journal, 3, 205-210.

Mengaud, L. 1908. Sur les environs de San Vicente de La Barquera. Compte rendu sommaire des séances de la Société géologique de France, 8, 544.

Mengaud, L. 1910. Tertiaire de la Province de Santander. BuIletin de la Société Géologique de France, 10, 30-33.

Mengaud, L. 1914. Sur la Tectonique des environs d'Infiesto, Arriondas et Ribadesella (Asturias). Comptes Rendus de I'Académie des sciences Paris, 158, 1381-1383.

Mengaud, L. 1920. Recherches sur la région cantabrique.Thése Univ. Toulouse, imprimerie Vve. Bonnet, 370 p.

Mengaud, L. 1932. Sur la structure de la Chaîne Cantabrique. Comptes Rendus de I'Académie des sciences Paris, 195, 1092-1094.

Navarro, D., Leyva, F. y Villa, E. 1986. Cambios laterales de facies en el Carbonífero del Oriente de Asturias (Cordillera Cantábrica, Norte de España). Trabajos de Geología (Univ. de Oviedo), 16, 87-102.

Nederlof, M. H. 1959. Structure and sedimentology of the upper Craboniferous of the upper Pisuerga valley, Cantabrian Mountains. Spain. Leidse Geologische Mededelingen, 24, 603-703.

Nederlof, M. H. y Sitter, L. U. de, 1956. La Cuenca carbonífera del río Pisuerga (Palencia). Boletín del Instituto Geológico y Minero de España, 68, 3-43.

Nollau, G. 1965. Ein Intrusivdiabas im Altpaläozoikum des Montes de León, in Nordwestspanien und seine Autometamorphen bis epizonal reginalmetamorphen Einformungan. Beiträge zur Mineralogie und Petrographie, 11, 662-694.

Nollau, G. 1968. Stratigraphie, Magmatismus undTektonik des Montes de León zwischen Astorga und Ponferrada in Nordwest Spanien. Geotektonische Forschungen, 27, 71-146.

Ortega Gironés, E. y Gil Ibarguchi, I. 1983. La unidad de Malpica-Tuy ("compleio antiguo", "fosa blastomilonítica"). En: Geología de España 1 (Libro Jubilar J. M. Ríos). Instituto Geológico y Minero de España, Madrid, 430-440.

Overmeeren, R. A. van, 1975. A gravity investigation of the catazonal rock complex at Cabo Ortegal (NW Spain). Tectonophysics, 26, 293-307

Paillete, A. 1845. Recherches sur quelques unes des roches qui constituent la province des Asturies (Espagne). Bulletin de la Société Géologique de France, (2 ${ }^{\mathrm{a}}$ ser), 2, 439-457. Paillete, A. y Verneuil, E. 1846. Sur quelques depôts carboni- 
M. Julivert, 2020. El progreso del conocimiento de la estructura geológica del noroeste... Boletín Geológico y Minero, 131 (4): $661-693$

fères des Asturies. Bulletin de la Société Géologique de France, (2 ${ }^{\mathrm{a}}$ ser), 3, 450-457.

Parés, J. M., Voo, R. van der, Stamtakos, J. y Pérez Estaún, A. 1994. Remagnetisatios and postfolding oroclinal rotation in the Cantabria (Asturian Arc, Northern Spain). Tectonics, 13, 1461-1471.

Parga Pondal, I. 1956. Nota explicativa del mapa geológico de la parte NO de la provincia de La Coruña. Leidse Geologische Mededelingen, 21, 467-484.

Parga Pondal, I. 1960. Observación, interpretación y problemas geológicos de Galicia. Notas y Comunicaciones del Instituto Geológico y Minero de España, 59, 333-358.

Parga Pondal, I. 1963. Mapa geológico-estructural de Galicia, E. 1:400.000. Instituto Geológico y Minero de España, Madrid.

Parga Pondal, I. 1966. La investigación geológica en Galicia. Leidse Geologische Mededelingen, 36, 207-310.

Parga Pondal, I. y López de Azcona, J. M. 1965. Sobre la existecia de elementos escasos en los granitos de Galicia. Notas y Comunicaciones del Instituto Geológico y Minero de España, 78, 221-236.

Parga Pondal, I., López de Azcona, J. M. yTorre Enciso, E. 1964. Mapa geológico de la provincia de La Coruña, E. 1:200.000. Instituto Geológico y Minero de España, Madrid.

Parga Pondal, I., Matte, P. y Capdevila, R. 1964. Introduction a la géologie de I'Ollo de Sapo. Formation porphyroïde antesilurienne du nord Ouest de l'Espagne. Notas y Comunicaciones del Instituto Geológico y Minero de España, 76, 119-164

Patac, I. 1920. La formación uraliense asturiana; estudios de cuencas carboníferas. Compañía Asturiana Artes Gráficas, Gijón, 54 pp.

Patac, I. 1932. Estudio geológico-minero de la cuenca hullera submarina de Arnao (Availés). Gráficas Marinas, Madrid, 55 pp.

Patac, I. 1933. Riquezas Minerales de España. La cuenca carbonífera de Gijón.T.Tip. Altamirano, Oviedo, 15 pp.

Pello, J. 1967. Estudio geológico de la prolongación del borde oriental de la Cuenca Minera Central de Asturias. Trabajos de Geología (Univ. de Oviedo), 1, 27-38.

Pello, J. y Phillippot, A. 1967. Sur la présence du Llanvirn en Puerto Sueve (zone orientale des Asturies, NW de l'Espagne). Compte rendu sommaire des séances de la Société géologique de France, 4, 156-157.

Pérez Estaún, A. 1971. La ventana tectónica de Villabandín (Antiforme del Narcea). Breviora Geologica Asturica, 15, 7-13

Pérez Estaún, A. 1978. Estratigrafía y estructura de la rama S de la Zona Asturoccidental-leonea. Memorias del Instituto Geológico y Minero de España, 92, 1-150

Pérez Estaún, A. 2005. El plan MAGNA, movilizador de la investigación geológica en España durante las décadas setenta y ochenta del siglo XX: la experiencia del noroeste de España. Boletín Geológico y Minero, 116 (4), 307-323.

Pérez-Estaún, A., Bastida, F., Alonso, J. L., Marquínez, J., Aller, J., Álvarez-Marrón, J., Marcos, A. y Pulgar, J.A. 1988. A thin-skinned tectonics model for an arcuate fold and thrust belt: The Cantabrian Zone (Variscan Ibero-Armorican Arc). Tectonics, 7, 517-537.

Pluum, B. A. van der, Savage, J. F. y Kars-Sijpesteijn, C. H. 1986. Variation in fold geommetry in the Yuso Basin, Northern Spain; implications for the deformation regime. Journal of Structural Geology, 8 (8), 879-886.

Poll, K. 1970. Stratigraphie und Tektonik an der Wende Silurium/Devon im westlichen Kantabrischen Gebirge (Nordspanien). Sitzungsberichte der Physikalisch-Medizinischen Sozietät Erlangen, 83/84, 32-176.

Prado, C. de, 1864. Descripción física y geológica de la provincia de Madrid. Junta General de Estadística, Madrid, 219 pp. (reedición de 1971, Colegio Ingenieros de Caminos Canales y Puertos, Madrid, 219 pp.).

Prado, C. de (Verneuil, E. de y Barrande, J.) 1860. Sur l'éxistence de la faune primordial dans la Chaîne Cantabrique (suivie de la description des fósiles par MM de Verneuil et Barrande). Bulletin de la Société Géologique de France (2éme ser.), 17, 516-554.

Puelles, P., Mulchrone, K. F., Ábalos, B. y Gil Ibarguchi, J. I. 2005. Structural analysis of high-pressure shear zones (Bacariza Formation, Cabo Ortegal, NW Spain). Journal of Structural Geology, 27, 1046-1060.

Rábano, I. 2015. Los Cimientos de la Geología. La Comisión del Mapa Geológico de España (1849-1910). Instituto Geológico y Minero de España, Madrid, 329 pp.

Rábano, I. 2019. La Comisión del Mapa Geológico de España en la Exposición Nacional de Minería de 1883: un escaparate de la construcción del mapa geológico nacional. Boletín de la Real Sociedad Española de Historia Natural, 113, 133-144.

Rábano, I. y Aragón, S. 2007. Nuevos datos históricos sobre la Comisión del Mapa Geológico de España. Boletín Geológico y Minero, 118 (4), 813-826.

Raumer, J. F. von, 1962. Geología del zócalo cristalino de la Península de Barbanza, cerca de Noya (La Coruña). Notas y Comunicaciones del Instituto Geológico y Minero de España, 68, 171-180.

Raumer, J. F. von, 1963. Geología del basamento del NO de España. Notas y Comunicaciones del Instituto Geológico y Minero de España, 72, 239-242.

Raven, J. G. M. y Pluijm, B. A. van der, 1986. Metamorphic fluids and transtension in the Cantabrian Mountains of Northern Spain: an application of the conodont colour alteration index. Geological Magazine, 123, 673-681

Reading, H. C. 1980. Characteristics and recognition of strike-slip fault systems. Special Publications International Association Sedimentology, 4, 7-20.

Ribeiro, A. 1970. Position structurale des massifs de Morais et Bragança (Tras-os-Montes). Comunicações dos Serviços Geológicos de Portugal, 54, 115-138.

Ribeiro, A. 1983. Los complejos de Bragança y Morais. En: Geología de España 1 (Libro Jubilar J. M. Ríos). Instituto Geológico y Minero de España, Madrid, 450-455.

Ribeiro, A., Cramez, C. y Rebelo, J. A. 1964. Sur la structure de 
M. Julivert, 2020. El progreso del conocimiento de la estructura geológica del noroeste... Boletín Geológico y Minero, 131 (4): $661-693$

Tras-os-Montes (nord-est de Portugal). Comptes Rendus de l'Académie des Sciences Paris, 258, 263-265.

Ribeiro, A., Madeiros, A. y Rebelo, J. A. 1966. Estado actual dos conhecimentos sobre a geologia de Tras-os-Montes oriental. Boletim da Sociedade Geológica de Portugal, 16 (1-2), 93-110.

Ries, A. C. y Shackleton, R. M. 1971. Catazonal complexes of Noth-Wesrt Spain and North Portugal, remnants of a hercynian thrust plate. Nature Physical Science, 234 (47), 65-68.

Ries, A. C. y Shackleton, R. M. 1976. Patterns of strain variation in arcuate foldbelts. Philosophical Transactions of the Royal Society of London. Series A, 283, 281-288.

Ries, A. C., Richarson, A. y Shackleton, R. M. 1980. Rotation of the Iberian Arc: paleomagnetic results from north Spain. Earth and Planetary Science Letters, 50, 301-310.

Ries, A. C. y Shackleton, R. M. 1976. Patterns of strain variation in arcuate fold belts. Philosophical Transactions of the Royal Society of London. Series A, 283, 281-288.

Rodríguez Fernández, L. R. 1978. La prolongación de las escamas de Tameza y La Sobia (Asturias, Cordillera Cantabrica). Trabajos de Geología (Univ. de Oviedo), 10, 389-399.

Rupke, J. 1965. The Esla nappe, Cantabrian Mountains, Spain. Leidse Geologische Mededelingen, 32, 1-74.

Santanach, P. (Ed.) 1995. Revista de la Sociedad Geologica de España, 8.

Santanach, P. 2015. Els mapes geològics més antics dels Pirineus i altres aportacions neptunistes. Treballs del Museu de Geologia de Barcelona, 21, 5-17

Savage, J. F. 1967. Tectonic analysis of Lechada and Curavaca synclines, Yuso basin, Leon, NW Spain. Leidse Geologische Mededelingen, 39, 193-247.

Schmidt Thomé, P. 1945. Paläozoisches Grundgebirge und junger Deckgebirge im Westlich Zentraspanien, Geotektonische Forschungen, 6 (trad. en Public. Extr. Geol. España, 5, 61-90).

Schulz, G. 1835. Descripción geognóstica del Reino de Galicia, acompañada de un mapa petrográfico de este país. Imprenta de los herederos de Collado, Madrid, 52 pp.

Schulz, G. 1858a. Descripción geológica de la Provincia de Oviedo. Imprenta y Librería de Don José Gonzalez, 138 pp.

Schulz, G. 1858b. Atlas geológico y topográfico de Asturias. Lit. de G. Pfeiffer, Madrid.

Sdzuy, K. 1967. Trilobites del Cámbrico medio en Asturias. Trabajos de Geología (Univ. Oviedo), 2, 77-134.

Seidlitz, W. von, 1931. Discordanz und Orogenese der Gebirge am Mittelmeer. Bornträger, Berlín, 651 pp.

Sitter, L. U. de, 1959. The Río Esla nappe in the zone of León of the Asturias Cantabrian Mountain Chain. Notas y Comunicaciones del Instituto Geológico y Minero de España, 56, 3-24.

Sitter, L. U. de, 1960. Cross-folding in the non-metamorphic of the Cantabrian Mountains and the Pyrenees. Geologie en Mijnbouw, 22 (39), 189-194.

Sitter, L. U. de, 1961. Le Precambrien dans la Chaîne Cantabrique. Compte rendu sommaire des séances de la Société géologique de France, 1961 (9), 253.

Sitter, L. U. de, 1962. The structure of the southern slope of the Cantabrian Mountains. Leidse Geologische Mededelingen, 26, 255-264.

Sitter, L. U. de, 1965a. The herynian cantabrian orogen. Mem. Geopal. Univ. Ferrara, 2 (3), 211-225.

Sitter, L. U. de, 1965b. Hercynian and Alpine orogenies in northern Spain. Geologie en Mijnbouw, 44 (11), 373-383.

Sitter, L. U. de y Bosch, W. J. van den, 1968. The structure of the SW. part of the Cantabrian Mountains. Leidse Geologische Mededelingen, 43, 213-216.

Sitter, L. U. de y Boschma, D. 1966. Explanation of the geological map of the Paleozoic of the southern Cantabrian Mountains. Leidse Geologische Mededelingen, 31, 191-238.

Sjerp, N. 1967. Geology of the San Isidro-Porma area (Cantabrian Mountais, Spain). Leidse Geologische Mededelingen, 30, 55-128.

Soler, M. 1967. Evolución longitudinal del cabalgamiento de La Sobia. Acta Geologica Hipanica, año 2 (4), 82-84.

Staalduinen, C. J. van, 1973. Geology of the area between the Luna and Torío rivers, southern Cantabrians, NW Sapin. Leidse Geologische Mededelingen, 49, 167-205.

Staub, R. M. 1926. Gedanken zur Tektonik Spaniens. Vierteljahrsschrift der Naturforschenden Gesellschaft Zürich, 71, 196-260 (versión española y prólogo por A. Carbonell, 1927, “Ideas sobre la tectónica de España", Real Academia de Ciencias, Bellas Letras y Nobles Artes de Córdoba, pp. 5-7, prólogo y pp. 8-83).

Stille, H. 1927. Über westmediterrane Gebirgszusammenhänge. Abhandlungen der Gesellschaft der Wissenschaften in Göttingen, Mathematisch-Physikalische Klasse, 12, 1-62.

Stewart, S. A. 1995. Paleomagnetic analysis of fold kinematics and implications for geological models of the Cantabrian/Asturian arc, north Spain. Journal of Geophysical Research, 100, 20079-20094.

Suárez, O. y Suárez, V. 1970. Sobre las rocas plutónicas de la zona de Tapia (Asturias, España). Boletín Geológico y Minero, 81 (2-3), 185-195.

Suess, E. 1885-1909. Das Antlitz der Erde. 1 (1885), 778 pp., 2 (1888), 703 pp., 3 (1) (1901), 508 pp., 3 (2) (1909), 789 pp., Tempsky, Wien.

Termier, P. 1905. Sur la structure géologique de la Cordillère Cantabrique dans la province de Santander. Comptes Rendus de l'Académie des Sciences Paris, 141, 920-922.

Termier, P. 1918a. Contribution a la connaissence de la tectonique des Asturias: las Peñas Careses. Comptes Rendus de I'Académie des Sciences Paris, 166, 709-714.

Termier, P. 1918b. Contribution a la connaissence de la tectonique des Asturias: anomalies au contact du Houiller et du Devonien d'Arnao. Comptes Rendus de I'Académie des Sciences Paris, 166 433-439.

Termier, P. 1918c. Contribution a la connaissence de la tectonique des Asturias: plis hercyniens et plis pyrénéens, charriages stephaniens et charriages postnummulitique. Comptes Rendus de l'Académie des Sciences Paris, 166, 793-799. 
Termier, P. 1918d. Contribution a la connaissence de la tectonique des Asturias: la signification des mylonites d'Arnao. Comptes Rendus de l'Académie des Sciences Paris, $166,516-520$.

Tex, E. den, 1966. Aperçu pétrologique et structural de la Galice cristalline. Leidse Geologische Mededelingen, 36, 211-222.

Tex, E. den, 1975. Thermally mantled domes: the case for convective heat flow in more or less solids orogenic Basement. Progress in Geodynamics (Royal Neder. Acad. Arts and Sc.), 62-79.

Tex, E. den, 1981a. Basement evolution in the northern Hesperian massif. A preliminary survey of results obtained by the Leyden Research Group. Leidse Geologische Mededelingen, 52, 1-21.

Tex, E. den, 1981b. A geological section across the Hesperian massif in western and central Galicia. Geologie en Mijnbouw, 60 (1), 33-40.

Tex, E. den, Engels, J. F. y Vogel, D. E. 1972. A high presure intermediate temperature facies series in the Precambrian at Cabo Ortegal (Northwest Spain). 24 International Geological Congress (Montreal). Sect. 2, 64-73.

Truyols, J. 1982. El Carbonífero en la obra de Barrois. Trabajos de Geología (Univ. de Oviedo), 12, 7-21.

Truyols, J. y Julivert, M. 1976. La sucesión paleozoica entre el Cabo Peñas y Antromero (Cordillera Cantábrica). Trabajos de Geología (Univ. de Oviedo), 8, 5-30.

Valdés, J. 1965. La tectónica de la zona de Los Oscos (Asturias). Estudios Geológicos, 20, 271-283.

Van Der Voo, R., Stamatakos, J.A. y Parés, J. M. 1997.- Kinematic constraints on thrust-belt curvature from syndeformational magnetizations in the Lagos del Valle Syncline in the Cantabrian Arc, Spain. Journal of Geophysical Research, 102, 10105-10120.

Vera, J. A. (Ed.) 2004. Geología de España. Instituto Geológico y Minero de España y Sociedad Geológica de España, Madrid, $885 \mathrm{pp}$.

Verneuil, E. y Collomb, E. 1864. Carte géologique de I'Espagne et du Portugal. 1:2.000.000. Paris.
Walter, R. 1965. Die unterchiedlkiche Entwicklung des Alt Paläozoikum östlich und westlich des Kristallins von Vivero-Lugo (Nordwest Spanien). Neues Jahrbuch für Geologie und Paläontologie Monatshefte, 12, 740-753.

Walter, R. 1966a. Resultados de investigaciones geológicas en el noreste de la provincia de Lugo (NO España). Notas y Comunicaciones del Instituto Geológico y Minero de España, 89, 7-16.

Walter, R. 1966b. Die Entwicklung des Altpaläozoicums in Nordost-Galician (NW Spanien). Zeitschrift der Deutschen Geologischen Gesellschaft, 115, 919-920.

Walter, R. 1968. Die Geologie in der Nodöstlichen Provinz Lugo (Nordwerst Spanien). Geotektonische Forschungen, 27, 3-70.

Weil, A. B., Van Deer Voo, R. y Van Der Pluijm, B. 2001. Oroclinal bending and evidence against the Pangea megashear:The Cantabria-Asturias arc (northern Spain). Geology, 29, 991-994.

Weil, A. B., Van Deer Voo, R., Van Der Pluijm, B. y Parés, J. M. 2000. The formation of an orocline by multiphase deformation: a paleomagnetic investigation of the Cantabrian Asturias Arc (northern Spain). Journal of Structural Geology, 22, 735-756.

Winkler Prins, C. F. 2013. El Instituto de Geología de la Universiad de Leiden y la Cordillera Cantábrica: una oportunidad perdida. Tierra y Tecnología, 44, 21-37

Zamarreño, I. 1972. Las litofacies carbonatadas del Cámbrico de la Zona Cantábrica (NW España) y su distribución paleogeográfica. Trabajos de Geología (Univ. de Oviedo), $118 \mathrm{p}$.

Zamarreño, I. y Julivert, M. 1967. Estratigrafía del Cambriano del oriente de Asturias y estudio petrográfico de las facies carbonatadas. Trabajos de Geología (Univ. de Oviedo), 1, 135-163.

Zeiller, R. 1884. Notas acerca de la flora hullera de Asturias. Boletín de la Comisión del Mapa Geológico de España, 1, 159-182. (Traducció de "Notes sur la flore houillère des Asturies". Mémoires Société Géologique du Nord, 1882).

Recibido: julio 2019

Revisado: noviembre 2019

Aceptado: enero 2020

Publicado: marzo 2021 